\title{
LAS CIUDADES MUNDIALES Y GLOBALES EN EL MEDIO INTERNACIONAL, UNA REVISIÓN TEÓRICO-METODOLÓGICA DESDE LAS RELACIONES INTERNACIONALES*
}

\author{
Ray Freddy LaRa Pacheco**
}

SUMARIO: 1. INTRODUCCIÓN.-2. DEFINICIÓN DE LAS REDES GLOBALES DE CIUDADES.-3. ANTECEDENTES TEÓRICOS SOBRE LA CIUDAD MUNDIAL Y GLOBAL.-4. LA INFLUENCIA DE LA CIUDAD GLOBAL EN LAS RRII.-5. LA CIUDAD GLOBAL Y LAS RRII DESDE LA FORMACIÓN DE LA RED DE CIUDADES MUNDIALES.-6. LA CIUDAD GLOBAL Y LAS RRII DESDE LAS TEORÍAS DE LA GOBERNANZA GLOBAL.-7. LA CIUDAD GLOBAL Y LAS RRII DESDE LAS TEORÍAS DEL ENSAMBLAJE.-8. CRÍTICA A LOS ESTUDIOS DE LA CIUDAD GLOBAL Y LAS RRII.-9. CONCLUSIONES.

\section{INTRODUCCIÓN}

1. En lo relativo a la política internacional, la importancia que han adquirido en los últimos años las ciudades en el campo internacional es variada. Cuando las ciudades trascienden sus relaciones de hermandad, cooperación, asociación y competencia con otras ciudades y son capaces de crear sus propias formas de interacción con otras ciudades -y demás actores internacionales-, sin la necesidad de un Estado-nación que las contenga u organismo internacional que les indiquen qué es lo mejor para ellas, se está en presencia de un reconocimiento global que proviene de las mismas ciudades y otros agentes internacionales. Esto es determinante ya que permite observar cómo ven a las ciudades los demás actores.

2. Para muchos especialistas en el campo de las Relaciones Internacionales (RRII), las ciudades no han sido estudiadas a fondo, algo que podría

* Todas las páginas web de referencia han sido consultadas por última vez el 10 de mayo de 2019.

** Profesor-Investigador Titular A del Departamento de Políticas Públicas en el Centro Universitario de Ciencias Económico Administrativas de la Universidad de Guadalajara (ray.lara@academicos. udg.mx). 
cuestionarse debido a más de medio siglo de estudios sobre la temática. A pesar de esta "relativa» omisión del estudio de las ciudades en la disciplina, hay algunos aspectos a destacar. El medio internacional ha estudiado las ciudades desde el amplio espectro de las Ciencias Sociales (CCSS), a través de diversas perspectivas teórico-conceptuales, distintas ideologías y diferentes enfoques (estatocéntrico, urbanocéntrico, gobernanza, etc.) y del mismo modo, pueden ser analizadas desde múltiples metodologías. Entre los temas centrales de estas perspectivas se enumeran las siguientes:

3. La ciudad: 1) como actor histórico; 2) como creadora de la diplomacia; 3) como actor internacional desde las RRII; 4) como piedra angular de la glocalización; 5) dentro de la división internacional del trabajo; 6) creadora de nuevas geografías; 7) como Gobierno No Central o actor paradiplomático; 8) la ciudad mundial como actor global; 9) la inserción internacional de la ciudad como política pública; 10) como actor en la gobernanza global; 11) en el orden legal global desde el nuevo municipalismo y su autonomía hasta el Derecho local internacional; 12) el alcalde y los liderazgos locales; 13) como territorio de posicionamiento e imagen, y 14) su identidad y el localismo.

4. El presente estudio se enfocará solo en una de estas perspectivas a través del recuento del estado de la cuestión de los estudios de las Ciudades Mundiales y revisión del concepto de Ciudades Globales desde las RRII, los cuales se han centrado en su influencia en la gobernanza global, su capacidad de creación de redes globales de interacción política y económica, así como su agencia como actor dentro del Sistema Internacional. Como cualquier perspectiva teórico-metodológica, ha recibido críticas que en su momento han tenido que resolver conforme se va consolidando una comunidad epistémica de la ciudad en la disciplina de las RRII.

5. Este estudio tiene como premisa de trabajo que la perspectiva de la Ciudad Global en la última década (2010-2019), ha sido la mejor posicionada en la literatura académica de las RRII — aunque no es la única一, debido a su transdisciplinariedad desde la Geografía Política, la Economía y la Sociología Urbana, así como al número de autores que la revisan a nivel mundial a partir de la década de los ochenta.

\section{DEFINICIÓN DE LAS REDES GLOBALES DE CIUDADES}

6. A finales de los setenta, se observaban ciertas ciudades que destacaban sobre las demás como centros de operaciones para el capital global y una jerarquía (aunque cambiante) entre tales ciudades - y las consecuencias sociales y políticas que tuvieron para ellas el hecho de ser tales puntos de base- - Así, a mediados de los años ochenta surge el enfoque de las ciudades mundiales (que posteriormente se llamaría ciudades globales) aunque sus antecedentes principales se pueden observar desde los sesenta con el libro de Peter Hall, The World Cities de 1966, donde se definía que este tipo de lugares se convertían en centros de poder político, comercio, 
servicios avanzados, de generación de talento, de consumo, entre otras funciones ${ }^{1}$.

7. Este nuevo paradigma teórico emergió en el ámbito de las universidades, en específico desde la Sociología Urbana y la Geografía Política, «como un campo bastante amplio para la investigación, con especialistas en diferentes disciplinas y países trabajando sobre la materia» ${ }^{2}$. En ese momento, y de ahí su importancia hasta el día de hoy, es que este paradigma de la ciudad global «se erige como una perspectiva teórica que sintetiza diversos procesos como el mercado laboral, la tecnología de la información, la migración, los estudios culturales, los procesos de construcción de la ciudad, la formación de clases sociales, el desempleo y la política urbana» ${ }^{3}$. En otras palabras:

«Esta literatura genera un número de contribuciones específicas a los análisis comparativos de ciudades, al comercio internacional de servicios y su impacto en las ciudades, en la economía global, incluyendo la organización de la economía y sus repercusiones espaciales [...] se puede ver en la variedad de autores y temas en varias colecciones que tratan sobre el estado actual de la técnica, y muchos otros que elaboran, critican y amplían la base empírica y, en general, avanzan sobre este proyecto teórico y metodológico» ${ }^{4}$.

8. Para poder entender las funciones y el actuar de este tipo de ciudades, es importante hacer referencia a la relevancia de las redes como un sistema organizacional. No queda duda de que en la actualidad los actores internacionales se organizan en redes. «En ello tuvo una importante contribución la existencia de lazos digitales globales, pues estos han permitido el desarrollo de un nuevo tipo de política territorial con alcance global» ${ }^{5}$. En esta línea las redes pueden entenderse como estructuras comunicativas para influir en el discurso, procedimientos y en el plan de acción de estos actores ${ }^{6}$. Desde el «enfoque de redes (network approach) se define a las estructuras como patrones persistentes de relaciones entre los agentes que pueden definirlas, habilitarlas y restringir a estos mismos agentes, al igual que en otros enfoques estructurales en las RRII, el interés en las estructuras de red se basa en sus efectos» ${ }^{7}$. Ejemplos de estas serían: 1 ) redes multilaterales; 2 ) redes sociales; 3) redes desde la sociedad civil; 4) redes de migrantes; 5) redes de defensa; 6) redes delictivas y terroristas; 7) redes de cooperación, y 8) redes empresariales y Empresa-red, entre otras.

1 Sus orígenes pueden observarse en trabajos de principios del siglo XX. Véase DavIS, D. E., «Cities in Global Context: A Brief Intellectual History», International Journal of Urban and Regional Research, vol. 29, 2005, núm. 1, pp. 92-109.

2 SASSEN, S., «Ciudades en la economía global: enfoques teóricos y metodológicos», EURE, vol. 24, 1998, núm. 71, pp. 5-25, esp. pp. 11-12.

3 Méndez, A. (coord.), Estudios urbanos contemporáneos, Ciudad de México, Miguel Ángel PorrúaUNAM-IIES, 2006, p. 65.

4 SASSEN, S., op. cit., nota 2, p. 10.

5 SASSEn, S., Una sociología de la globalización, Madrid, Katz Editores, 2007, p. 22.

${ }^{6} \mathrm{Keck}$, M. y SIKKInK, K., Activistas Sin Fronteras: Redes de defensa en política Internacional, Ciudad de México, Siglo XXI editores, 2000.

7 Hafner-Burton, E., Kahler, M. y Montgomery, A., «Network Analysis for International Relations», International Organization, 2009, núm. 63, pp. 559-592, esp. p. 561. 
9. Estas redes son mecanismos en los que los actores negocian los espacios, los significados sociales, culturales y políticos de su esfuerzo conjunto; ya que "cuando hablamos de "redes de ciudades", "redes sociales", etc., la palabra "red" tiene un significado más abstracto o metafórico. Se define como un conjunto estable de relaciones entre actores, vistas como relaciones entre los lugares donde se encuentran esos mismos actores» ${ }^{8}$. Independientemente de que las redes sean sociales, de cooperación, defensa, entre otras, son las responsables de muchas de las estructuras de poder e influencia en nuestro mundo. No siempre es fácil reconocer su estructura y comportamiento. Es por ello que su visualización y el análisis de redes pueden contribuir notablemente a conocerlas ${ }^{9}$.

10. Dentro de las RRII se «han considerado a las redes como un modo particular de organización que se distinguen de los mercados o la jerarquía estatal» ${ }^{10}$. En específico en los enfoques de la Economía Política, como lo señala Peter J. Taylor, «el problema con ello es que las redes tienden a ser descuidadas por no ser centrales para la comprensión del Mercado o el Estado» ${ }^{11}$. Debido a ello, es importante asumir a las Redes como una forma de organización social equiparable al Mercado y al Estado como se observa en la Tabla 1. Ya que permite otro tipo de relaciones más allá de las internacionales y/o interestatales, que podrían ser asumidas como transnacionales y transurbanas.

Tabla 1. Formas de organización social

\begin{tabular}{|c|c|c|c|}
\hline $\begin{array}{c}\text { Atributos } \\
\text { principales }\end{array}$ & Mercados & Jerarquías & Redes \\
\hline Estructura social & Descentralizada & Piramidal & Horizontal \\
\hline Agentes & Independientes & Dependientes & Interdependiente \\
\hline Activación & Contratos/Leyes & Costumbres/Reglas & $\begin{array}{c}\text { Reciprocidad/ } \\
\text { Confianza }\end{array}$ \\
\hline Relaciones sociales & $\begin{array}{c}\text { Competitividad } \\
\text { igualitaria }\end{array}$ & $\begin{array}{c}\text { Competitividad } \\
\text { desigual }\end{array}$ & Cooperativa \\
\hline Atributo clave & Régimen de precios & Burocrático & Mutualidad \\
\hline Antítesis & Monopolio & Anarquía & Atomización \\
\hline $\begin{array}{c}\text { Principal esfera } \\
\text { de actividad }\end{array}$ & Económica & Política & Social \\
\hline
\end{tabular}

Fuente: TAYlor, P. J., 2011 (adaptada de Powell, 1990, y Thompson, 2003, traducción propia).

8 Dematteis, G., «Global networks, local cities», Flux, 1994, núm. 15, pp. 17-23, esp. p. 18.

9 Dürsteler, J. C., «Visualización de Redes Sociales», Revista digital InfoVis.net, 2003, núm. 136.

10 Hafner-Burton, E., et al., op. cit., nota 7, p. 559.

11 TAYLOR, P. J., «World city networks: measurement, social organization, global governance, and structural change», en Amen, M. M., McCarney, P. L., Toly, N. J. y Segbers, K. (eds.), Cities and global governance: new sites for international relations, Farnham, Ashgate Publishing, 2011, pp. 201-216, esp. p. 202. 
11. Según Emilie Hafner-Burton, et al., el análisis de redes «desafía las visiones convencionales de poder en las RRII mediante la definición del poder de la red en tres distintas formas: acceso (access), intermediación (brokerage) y opciones de salida (exit options)» ${ }^{12}$. Tomando en consideración esta idea, y con relación al poder de las ciudades que «puede interpretarse como una capacidad (poder sobre) y como un medio (poder de), las ciudades mundiales son tratadas como centros de servicio global y la red de ciudades mundiales puede ser conceptualizada como una red "entrelazada" (interlocked) de servicios empresariales y financieros de las empresas globales» ${ }^{13}$.

12. Este tipo de ciudades y sus redes de interacción son concebidos desde que «el sistema global emergente de las relaciones económicas asume su forma material, a través de las localidades urbanas. El modo específico de su integración da lugar a una jerarquía urbana de influencia y control llamadas ciudades mundiales» ${ }^{14}$, las cuales construyen las redes globales que «son similares a las que forman otros actores internacionales (jerárquicamente concebidas, excluyentes y diferenciadas con otras redes). Ya que son redes donde las empresas, industrias globales, los servicios avanzados entre ellas la electrónica, microelectrónica, biotecnología, nanotecnología, computación, forman redes de producción global» ${ }^{15} \mathrm{O}$, en otras palabras, circuitos globales especializados ${ }^{16}$. Por otro lado, «existen redes de ciudades conectadas por comercio y comunicación» ${ }^{17}$, así como por elementos políticos y sociales. En opinión de Manuel Castells:

«Los sistemas de comunicaciones avanzadas crean una nueva geografía, caracterizada por la concentración y a la vez por la descentralización, que en este caso, argumenta, no son conceptos opuestos sino que únicamente describen nuestra propia realidad. La realidad demuestra que estamos generando una arquitectura espacial de concentración-descentralización, tanto en el entorno urbano como en los flujos de población y actividades. Ya no podemos hablar de centro y periferia sino de diferentes centros conectados entre sí. Y el verdadero impacto de las telecomunicaciones es su capacidad de concentrar y descentralizar dentro de una misma concentración urbana» ${ }^{18}$.

$12 \mathrm{El}$ «análisis de redes tiene como objetivo identificar patrones de relaciones, hubs, grupos e intermediarios así como su vinculación de esas relaciones con los intereses de los actores». Sobre la importancia y las características centrales del análisis de redes en las RRII se recomienda HAFNER-BURTON, E. et al., op. cit., nota 7, pp. 559-592.

13 Taylor, P. J., Walker, D. R. F., Catalano, G. y Hoyler, M., «Diversity and Power in the World City Network», Cities, vol. 19, 2002, núm. 4, p. 231.

14 FriedmanN, J. y Goetz, W., «World City Formation: An agenda for research and action», International Journal of Urban and Regional Research, vol. 6, 1982, núm. 3, pp. 309-344, esp. p. 310.

15 LARA, R. F., Guadalajara como medio innovador y su proceso de conformación hacia una tecnópolis, Tesis para obtener el grado de Maestro en Ciencias Sociales, Universidad de Guadalajara, 2009, p. 72 .

16 SASSEN, S., «Localizando ciudades en circuitos globales», EURE, vol. 29, 2003, núm. 88, pp. 5-27.

17 Steinberg, F., Garnelo, M. L. y Zwanenburg, M. (comps.), «Avances en la Agenda Urbana: Santa Cruz de la Sierra», Documento de Trabajo Santa Cruz, Proyecto SINPA, 2001, p. 4.

18 CASTElls, M., "Manuel Castells expone su visión de las ciudades y el urbanismo», Gestión Urbana. La web para aprender de otras ciudades y ciudadan@s, 2008,http://www.gestionurbana.es/?p=194. 
13. Con dicha información, estas redes globales de ciudades pueden ser definidas de la siguiente manera:

«Es una estructura en la cual los nodos son las ciudades, conectadas por vínculos de naturaleza socioeconómica, a través de los cuales se intercambian flujos de distinta naturaleza, sustentados sobre infraestructuras de transporte y comunicaciones. Las principales características de las redes de ciudades son la posibilidad de coexistencia de estructuras jerárquicas y no-jerárquicas, la cooperación entre ciudades y la generación de ventajas asociadas a la organización de la estructura urbana y la interacción entre sus nodos» ${ }^{19}$.

14. Estas redes globales de ciudades provienen del concepto de ciudades mundiales y/o globales que destacan el nexo entre el crecimiento urbano y el desarrollo económico mundial. Especialmente existe la tesis de que «el sistema mundial de la producción y de los mercados está articulado territorialmente en forma de una red mundial de ciudades. La internacionalización y la globalización avanzadas del capital necesitan centros de coordinación y de control de las actividades económicas mundiales» ${ }^{20}$, donde "en la literatura actual sobre ciudades globales, el factor determinante es el de una red global de ciudades transfronterizas que funcionan como sitios estratégicos para las operaciones económicas globales» ${ }^{21}$.

15. Peter J. Taylor señala que «dentro de la teoría urbana la mayoría de sus perspectivas centran su análisis en las relaciones internas de las ciudades, ello solo proporciona una comprensión parcial de este objeto de estudio. Las ciudades históricamente han operado en grupos que forman redes de actividades [...] este conjunto de actividades están relacionadas entre sí con otros grupos de actividades en otras ciudades» ${ }^{22}$. En el contexto actual, «el sistema urbano global es una red, no una pirámide. Y la relación cambiante respecto a esa red determina, en buena medida, la suerte de ciudades y ciudadanos» ${ }^{23}$. Y «profundamente conflictiva, aunque sea una red ${ }^{24}$ donde «la conectividad de redes globales de las grandes metrópolis probablemente se va a intensificar» ${ }^{25}$, y "cada una de estas ciudades metropolitanas tienen la exigencia de pertenecer a estas redes, ya que forman parte del proceso de producción global donde las empresas transnacionales y las ciudades están en una relación permanente» ${ }^{26}$.

19 BoIX, R., Redes de ciudades y externalidades, Tesis para obtener el grado de Doctor en Economía Aplicada, Universitat Autónoma de Barcelona, 2003, p. 17.

20 KRÄTKe, 1997, citado por HeINEBERG, H., «Las metrópolis en el proceso de globalización», Revista Bibliográfica de Geografía y Ciencias Sociales, vol. X, 2005, núm. 563, http://www.ub.es/geocrit/b3w563. htm.

21 SASSEN, S., op. cit., nota 2, p. 11.

${ }^{22}$ TAYlor, P. J., «Leading World Cities: Empirical Evaluations of Urban Nodes in Multiple Networks», Urban Studies, vol. 42, 2005, núm. 9, pp. 1593-1608, esp. p. 1594.

23 Borja, J. y CAStells, M., Local y Global. La Gestión de las ciudades en la era de la información, 2. ${ }^{a}$ ed., Ciudad de México, Taurus, 2006, p. 43.

${ }^{24}$ Torrijos, V., Política exterior y relaciones internacionales, Bogotá, Universidad del Rosario, 2009, p. 361 .

25 HeINEBerg, H., op. cit., nota 20.

26 LARA, R. F., op. cit., nota 15, p. 75. 
16. En otras palabras, "con el surgimiento de la actual red de ciudades mundiales se está anunciando un nuevo modus vivendi [con base en los planteamientos de Immanuel Wallerstein] entre las funciones de "guardián" y "comerciante" [con base en los planteamientos de Jane Jacobs] tanto en la teoría como en la práctica. Este es el mensaje de un mundo multi-escalar que está emergiendo, con ello lo multi-escalar es igual a un contenedor muy poroso. Si bien la globalización presagia la erosión del Estado-nación, esto no representa per se su fin» ${ }^{27}$.

\section{ANTECEDENTES TEÓRICOS SOBRE LA CIUDAD MUNDIAL Y GLOBAL}

17. Por su parte, Giuseppe Dematteis mantiene que «las ciudades están aumentando su capacidad de acción (autónoma); ya que han creado una red de relaciones de competencia y cooperación que se extienden más allá de los límites nacionales y la capacidad de control de los Estados» ${ }^{28}$. Por ejemplo, desde finales de los años setenta, «los análisis de la economía global ya habían apuntado a la tesis de la nueva división del trabajo y la formación de un sistema mundial de producción y mercados, donde el proceso de globalización de la economía es elemento clave en el examen de los patrones de urbanización de algunas ciudades» ${ }^{29}$; ya que "los mercados tanto nacionales como globales así como las organizaciones integradas globalmente requieren de lugares céntricos donde se pueda realizar el trabajo de la globalización. Los servicios corporativos financieros y avanzados son industrias que producen las mercancías organizativas necesarias para la puesta en práctica y la gestión de los sistemas de economía globales» ${ }^{30}$.

18. John Friedmann y Goetz Wolff declaran en su artículo «World city formation: an agenda for research and action» de 1982 que el papel de las ciudades en el sistema mundial debe determinarse mediante las investigaciones empíricas ${ }^{31}$.

27 TAYlor, P. J., «Problematizing City/State relations: Towards a geohistorical understanding of contemporary globalization", Transactions of the Institute of British Geographers, vol. 32, 2007, núm. 2, pp. 133-150, esp. p. 141.

28 Dematteis, G., op. cit., nota 8, p. 17.

29 MéndeZ, A., op. cit., nota 3, p. 55.

30 SAssen, S., "The Global City: Introducing a Concept», The Brown Journal of World Affairs, vol. XI, 2005, núm. 2, p. 31, http://www.saskiasassen.com/pdfs/publications/the-global-city-brown.pdf.

31 Alejandro Méndez identifica en términos esquemáticos los tres momentos en el desarrollo metodológico del concepto de la ciudad mundial o global: 1) Propuesta de la agenda de investigación. Las ciudades mundiales son el vínculo entre la economía mundial y el Estado-nación. En otras palabras, «un marco de investigación en el que conectaba el proceso de urbanización con la división internacional del trabajo, o en nuestra terminología, la localidad con la economía-mundo" (TAYLOR y FLINT, 2002: 359) todo ello en el marco de la nueva división internacional de trabajo. 2) Formulación de la hipótesis. Lo que había sido una hipótesis a comienzos de los ochenta se transformó en una teorización y especificación empírica a cabalidad durante los noventa y principios del siglo XXI con los trabajos de Manuel Castells y Saskia Sassen. 3) Desarrollo de investigaciones sobre la formación de la ciudad global. Desde los noventa hasta nuestros días, la construcción del paradigma de la ciudad 
«La pregunta medular consiste en cómo estas regiones urbanas están siendo integradas al sistema global de relaciones económicas, considerando principalmente dos elementos: 1) la forma e intensidad de la integración de la ciudad, por ejemplo, como lugar de las corporaciones transnacionales, como centroperiferia, como centro ideológico o como mercado mundial, y 2) la dominación especial asignada por el capital a la ciudad, ya sea global o multinacional, articulando economías nacionales con el sistema mundial» ${ }^{32}$.

19. La tesis principal «vincula el proceso de urbanización con las fuerzas económicas mundiales. Las ciudades mundiales son puntos básicos del capital mundial, aunque se reconoce que la variable económica se conserva como decisiva, también interviene el pasado histórico, las políticas nacionales y la cultura» ${ }^{33}$. Esta perspectiva promueve que el resultado de «la transformación de la economía internacional a la global, que se registra ostensiblemente entre la década de los setenta y ochenta; en esos años la economía internacional había sido considerada como expresión de los acuerdos y tratados regulados por los Estados-nación. En cambio en la economía global, los bienes servicios son en esencial producidos y distribuidos por un sistema oligopólico de redes corporativas globales, cuyas operaciones rebasan las fronteras nacionales y las regulaciones del Estadonación» ${ }^{34}$.

20. Posteriormente, en su artículo «The World City Hypothesis» de 1986, John Friedmann desarrolló su hipótesis central sobre las ciudades mundiales, que en realidad son siete. En ellas considera a «la ciudad mundial como un principal centro financiero con oficinas centrales de empresas transnacionales, con instituciones internacionales, con un rápido incremento del sector de servicios al productor, como un importante centro de la producción, como un principal nudo de transporte, a lo que añadió el criterio del número de los habitantes ${ }^{35}$.

21. Es importante hacer la mención que la interpretación de los postulados de la hipótesis de la ciudad mundial, al menos los de la Tabla 2, hacen referencia al actuar de la ciudad en el medio internacional, en la división internacional del trabajo y en la dinámica interna dentro de su estado contenedor, a través del análisis estructuralista de la geografía política Taylor y Flint, así como de los estudios urbanos liberales de Méndez. Así Friedmann sostiene que «este programa de investigación tenía como objetivo observar los efectos estructurales de la inserción ciudades en el orden global» ${ }^{36}$.

global consiste en la formulación de nuevas tesis y críticas sobre el tema. Véase MÉNDEZ, A., op. cit., nota 3 .

32 FriedmanN, J. y Goetz, W., op. cit., nota 14, pp. 310-311.

33 Méndez, A., op. cit., nota 3, p. 62.

34 Ibid., p. 55.

35 Heineberg, H., op. cit., nota 20.

36 FriedmanN, J., "World Cities Revisited: A Comment», Urban Studies, vol. 38, 2001, núm. 13, pp. 2535-2536, esp. p. 2536. 
Tabla 2. Las Siete Hipótesis de la Ciudad Mundial según John Friedmann, revisada por Peter Taylor, Colin Flint y Alejandro Méndez

\begin{tabular}{|c|c|c|c|}
\hline$\#$ & $\begin{array}{l}\text { J. Friedmann } \\
(1986,1995)\end{array}$ & $\begin{array}{l}\text { P. Taylor y C. Flint } \\
(2002)\end{array}$ & $\begin{array}{l}\text { A. Méndez } \\
\text { (2006) }\end{array}$ \\
\hline 1 & $\begin{array}{l}\text { While cities are social and } \\
\text { political entities, the eco- } \\
\text { nomic variable is para- } \\
\text { mount. Therefore, the form } \\
\text { and extent of a city's in- } \\
\text { tegration with the world } \\
\text { economy, and the function } \\
\text { assigned to the city in the } \\
\text { new spatial division of la- } \\
\text { bour, will be decisive for any } \\
\text { structural changes within it. }\end{array}$ & $\begin{array}{l}\text { Tesis de la integración. Las } \\
\text { oportunidades y limitacio- } \\
\text { nes a las que se enfrentan } \\
\text { las ciudades (o las locali- } \\
\text { dades) dependen de la na- } \\
\text { turaleza de su integración } \\
\text { en la cambiante división } \\
\text { mundial del trabajo. }\end{array}$ & $\begin{array}{l}\text { Los cambios estructurales } \\
\text { de la ciudad están rela- } \\
\text { cionados con la forma de } \\
\text { integración de la ciudad, } \\
\text { con la economía mundial } \\
\text { y con las funciones asigna- } \\
\text { das en esta integración. }\end{array}$ \\
\hline 2 & $\begin{array}{l}\text { Key cities throughout the } \\
\text { world are used by global } \\
\text { capital as "basing points» } \\
\text { in the spatial organization } \\
\text { and articulation of produc- } \\
\text { tion and markets. These key } \\
\text { cities or basing points may } \\
\text { be termed «world cities» (or } \\
\text { "global cities»). }\end{array}$ & $\begin{array}{l}\text { Tesis de la jerarquía. Algu- } \\
\text { nas ciudades, en tanto que } \\
\text { pilares del capital para la } \\
\text { organización espacial de } \\
\text { los mercados y la produc- } \\
\text { ción, se pueden organizar } \\
\text { en una jerarquía mundial } \\
\text { de centros de control. }\end{array}$ & $\begin{array}{l}\text { El capital global utiliza a } \\
\text { las ciudades como puntos } \\
\text { básicos en la organización } \\
\text { espacial y en la articula- } \\
\text { ción de la producción y los } \\
\text { mercados, formando una } \\
\text { jerarquía espacial comple- } \\
\text { ja de ciudades mundiales. }\end{array}$ \\
\hline 3 & $\begin{array}{l}\text { The driving force of world } \\
\text { city growth is found in a } \\
\text { small number of rapidly ex- } \\
\text { panding sectors: corporate } \\
\text { headquarters, international } \\
\text { finance, global transport } \\
\text { and communications, and } \\
\text { high level business services } \\
\text { (production services). }\end{array}$ & $\begin{array}{l}\text { Tesis de la producción. Las } \\
\text { funciones globales de las } \\
\text { ciudades mundiales están } \\
\text { representadas directamen- } \\
\text { te en la estructura socio- } \\
\text { espacial de la localidad. }\end{array}$ & $\begin{array}{l}\text { El papel que cumplen las } \\
\text { ciudades globales en cuan- } \\
\text { to a las funciones de con- } \\
\text { trol global que se refleja en } \\
\text { la estructura y la dinámica } \\
\text { de sus sectores producti- } \\
\text { vos y del empleo. }\end{array}$ \\
\hline 4 & $\begin{array}{l}\text { World cities are major sites } \\
\text { for the concentration and } \\
\text { accumulation of interna- } \\
\text { tional capital. }\end{array}$ & $\begin{array}{l}\text { Tesis de la acumulación. } \\
\text { Las ciudades mundiales } \\
\text { son las sedes principales } \\
\text { de la concentración y acu- } \\
\text { mulación del capital inter- } \\
\text { nacional. }\end{array}$ & $\begin{array}{l}\text { Las ciudades mundiales } \\
\text { representan sitios de con- } \\
\text { centración y acumulación } \\
\text { de capital internacional. }\end{array}$ \\
\hline 5 & $\begin{array}{l}\text { World cities are points of } \\
\text { destination for large num- } \\
\text { bers of both domestic and/ } \\
\text { or international migrants. }\end{array}$ & $\begin{array}{l}\text { Tesis de la emigración. Las } \\
\text { ciudades mundiales se } \\
\text { han convertido en polos } \\
\text { de atracción para los emi- } \\
\text { grantes internacionales } \\
\text { dando origen a una gran } \\
\text { diversidad étnica. }\end{array}$ & $\begin{array}{l}\text { Las ciudades mundiales } \\
\text { son sitios de destino de los } \\
\text { migrantes tanto del lugar } \\
\text { como internacionales. }\end{array}$ \\
\hline
\end{tabular}




\begin{tabular}{|c|l|l|l|}
\hline$\#$ & \multicolumn{1}{|c|}{$\begin{array}{c}\text { J. Friedmann } \\
(\mathbf{1 9 8 6 , 1 9 9 5 )}\end{array}$} & \multicolumn{1}{|c|}{$\begin{array}{c}\text { P. Taylor y c. Flint } \\
\text { (2002) }\end{array}$} & \multicolumn{1}{c|}{$\begin{array}{c}\text { A. Méndez } \\
\text { (2006) }\end{array}$} \\
\hline 6 & $\begin{array}{l}\text { World city formation brings } \\
\text { into focus the major con- } \\
\text { tradictions of industrial } \\
\text { capitalism, in particular, } \\
\text { class and spatial polariza- } \\
\text { tion. }\end{array}$ & $\begin{array}{l}\text { Tesis de la polarización. } \\
\text { Esa mezcla social inte- } \\
\text { ractúa con las funciones } \\
\text { económicas originando } \\
\text { segregación espacial en } \\
\text { una localidad polarizada } \\
\text { socialmente. }\end{array}$ & $\begin{array}{l}\text { La formación de la ciudad } \\
\text { conserva las contradiccio- } \\
\text { nes de capitalismo indus- } \\
\text { trial, manifestándose en la } \\
\text { polarización de las clases } \\
\text { sociales. }\end{array}$ \\
\hline 7 & $\begin{array}{l}\text { World city growth generates } \\
\text { social costs at rates that } \\
\text { tend to exceed the fiscal ca- } \\
\text { pacity of the State. }\end{array}$ & $\begin{array}{l}\text { Tesis del coste social. La } \\
\text { nueva polarización crea } \\
\text { un potencial de costes } \\
\text { sociales que supera la ca- } \\
\text { pacidad fiscal de la admi- } \\
\text { nistración local y regional } \\
\text { provocando crisis de las } \\
\text { que quedan a salvo de fun- } \\
\text { ciones de control de capi- } \\
\text { tal global. }\end{array}$ & $\begin{array}{l}\text { El crecimiento de la ciu- } \\
\text { dad mundial genera costos } \\
\text { pociales que exceden la ca- }\end{array}$ \\
\hline
\end{tabular}

Fuente: elaboración propia.

22. Estas ciudades son una manifestación material del control que reside en el centro y en la semiperiferia ${ }^{37}$. «Están ubicadas en el punto de contacto entre el sistema interestatal y el capital transnacional. Como tales, son la expresión contemporánea de la contradicción entre el espacio continuo en el que opera el capital y el espacio territorial de la política» ${ }^{38}$. La clasificación de Friedmann ${ }^{39}$ "señala en orden descendente, las articulaciones espaciales (ciudades mundiales): 1) articulaciones financieras globales (p. ej., Londres); 2) articulaciones multinacionales (p. ej., Miami); 3) articulaciones nacionales importantes (p. ej., París), y 4) articulaciones subnacionales/regionales (p. ej., Osaka-Kobe)» ${ }^{40}$.

23. El programa de investigación de Friedmann para muchos especialistas no era empíricamente suficiente, ya que le faltaban las pruebas de la exis-

37 «Friedmann retoma la clasificación de Wallerstein: centro, semiperiferia y periferia. El centro contiene las corporaciones transnacionales. La semiperiferia se considera como las áreas de rápida industrialización. La periferia está integrada por sociedades predominantemente agrarias, considerando que lo nuevo es que el actual sistema de empresas transnacional de la economía no tiene límites». MÉnDEZ, A., op. cit., nota 3, pp. 60-61.

38 Taylor, P. J. y Flint, C., Geografía Política: economía-mundo, Estado-nación y Localidad, Madrid, Trama editorial, 2002, p. 360.

39 «A diez años de la publicación de su artículo y con las críticas a este sobre la hipótesis de las ciudades, Friedmann escribiría en 1995, "Where we stand: a decade of world city research", un estado de la cuestión de la ciudad global, en este documento discute el objeto teórico de la investigación de la ciudad global. Él define a la ciudad como sistema socioeconómico organizado espacialmente, por tanto, se toma los lugares y sitios más que a los actores». Méndez, A., op. cit., nota 3, p. 64. Y en 2001: World Cities Revisited: A Comment.

40 Beaverstock, J. V., Smith, R. G. y Taylor, P. J., «A Roster of World Cities», Cities Journal, 1999, núm. 6, pp. 445-458, esp. p. 447. 
tencia de estas relaciones dentro del sistema o de la red de ciudades globales (conectividad de redes globales de las grandes metrópolis). Así, los trabajos de Saskia Sassen y el GaWC han tratado de llenar este vacío mediante su proyecto de investigación. Por una parte, Sassen opina que «un enfoque basado en la red de las dinámicas transfronterizas entre ciudades globales nos permite entender mejor la creciente presencia de estas transacciones en otros terrenos: político, cultural, social y criminal ${ }^{41}$. Esta autora también propone siete hipótesis para la formulación teórica del modelo de la ciudad global, que se citan in extenso:

«1. La dispersión geográfica de las actividades económicas que trae consigo la globalización es, junto con la integración simultánea de dichas actividades, un factor clave a la hora de alimentar el crecimiento y la importancia de funciones corporativas centrales.

2. Estas funciones centrales se vuelven tan complejas que las sedes centrales de las grandes empresas globales empiezan a exteriorizarlas, es decir, a contratar una parte de sus funciones centrales con empresas de servicios altamente especializadas: contabilidad, asesoría legal, relaciones públicas, programación informática, telecomunicaciones, etc.

3. Estas empresas especializadas en servicios que operan en mercados cada vez más complejos y globales están sujetas a una economía de aglomeración.

4. Cuanto más exteriorizan sus funciones las sedes centrales más complejas, menos estandarizadas, en especial aquellas sujetas a mercados cambiantes e inciertos, y más libres son de optar por cualquier emplazamiento geográfico; porque cada vez es menor la carga de trabajo que se lleva a cabo en la sede central y que, por tanto, es vulnerable a las economías de aglomeración.

5. Estas empresas especializadas en servicios necesitan proporcionar un servicio global que se traduzca en una red global de afiliados o alguna otra modalidad asociativa, lo que ha favorecido un fortalecimiento de las transacciones $\mathrm{y}$ las redes transfronterizas o interurbanas.

6. El número creciente de profesionales de alto nivel y empresas de servicios altamente especializadas ha agudizado la desigualdad espacial y socioeconómica presente en estas ciudades. El papel estratégico de estos servicios especializados ha revalorizado el mercado de profesionales de primer nivel, que también ha aumentado cuantitativamente.

7. Resultado de las dinámicas descritas en la sexta, es la de la creciente informalización de toda una serie de actividades económicas que cuentan con una demanda efectiva en estas ciudades y, sin embargo, tienen tasas de beneficios que no les permiten competir por determinados recursos con las grandes empresas situadas en lo más alto del sistema» ${ }^{42}$.

24. En este momento solo las formas que pueden describir este reconocimiento global, son los modelos académicos que muestran la trascendencia de la internacionalidad por la transnacionalidad de las redes globales de

41 SASSEN, S., "La Ciudad Global: Una introducción al concepto y su historia», en Grupo BBVA (ed.), Las múltiples caras de la globalización, Madrid, Artes Gráficas Palermo, 2009, p. 61, https://www. bbvaopenmind.com/libros/las-multiples-caras-de-la-globalizacion/.

42 SASSEN, S., op. cit., nota 41, pp. 51-53. 
ciudades: 1) Formación de la Red Mundial de Ciudades (World City Network Formation) de Peter J. Taylor y los miembros del GaWC ${ }^{43}$.

25. Por una parte Michele Acuto, analizando este programa de investigación, observa que se puede caracterizar a la ciudad global como una entidad urbana y social. La cual posee cinco características esenciales: 1) sirve como un nodo que articula los flujos globales; 2) realiza funciones múltiples y significativas de la ciudad mundial; 3) contiene funciones centrales de mando; 4) mantiene un orden urbano que equilibra: agregación y dispersión, y 5) desarrolla proyectos de orden global a través actividades empresariales. Esta tipología implica que cada ciudad global es una ciudad mundial (no viceversa) y el papel articulatorio típico de estas últimas se llevan a cabo por las primeras a escala global ${ }^{44}$.

26. Por otra parte, uno de los primeros trabajos del GaWC fue «A roster of world cities» donde intervinieron P. J. Taylor, J. V. Beaverstock y R. G. Smith (1999). En él se propone una lista o inventario de las ciudades mundiales, que hasta ese momento no había, y para ello identificaron las perspectivas teóricas de la tradición funcional - la otra es la escuela demográfica-. Posteriormente, tomaron las características de la ciudad global de Sassen que «implica dar primacía a las redes económicas debido a la naturaleza de las industrias que operan en ellas: las finanzas y los servicios especializados - contables (accountancy), publicidad y mercadotecnia (advertising), actividades bancarias y financieras (banking) y servicios legales (legal services)—, así como los nuevos sectores multimedia y de las telecomunicaciones ${ }^{45}$. Estas industrias se caracterizan por redes transfronterizas y divisiones especializadas de funciones entre ciudades antes que por la competencia entre países.

«Hoy en día existe una red mundial de ciudades que es de alcance global. Esta red es producto del surgimiento de las corporaciones multinacionales durante la segunda mitad del siglo Xx [...] durante 1970 y 1980, las firmas de avanzada (financieras, profesionales y creativas) que proveyeron dichos servicios tuvieron también que "hacerse globales". [...] Como esto no podía hacerse desde una sola ciudad, tuvieron que desarrollar redes de oficinas en varias ciudades, en ocasiones en cientos de ellas. Esto se debió que su trabajo combinaba conocimientos sobre servicios con alto valor agregado y conocimientos geográficos locales (económicos, culturales y políticos) relativos a los lugares donde prestarían los servicios. [...] Su tarea es eliminar cualquier obstáculo en el espacio económico global para que las corporaciones operen en un mundo de la manera más neoliberal posible» ${ }^{46}$.

43 Sobre el origen del GaWC, véase TAYLOR, P. J., «Hierarchical tendencies amongst world cities: a global research proposal», Cities, vol. 14, 1997, núm. 6, pp. 323-332. Así como el sitio web: https://www. lboro.ac.uk/gawc/.

${ }_{44}$ Acuto, M., "Finding the global city: An analytical journey through the "invisible college" ", Urban Studies, vol. 48, 2011, núm. 14, pp. 2953-2973, esp. p. 2968.

45 SASSEN, S., op. cit., nota 41, pp. 60-61.

46 TAYlor, P. J., "La red de ciudades mundiales y el planeta de los barrios pobres: acceso y exclusión en la globalización neoliberal», en Alfie, M., Azuara, I., Bueno, C., Pérez, M. y TAmayo, S. (coords.), Sistema Mundial y nuevas geografías, Ciudad de México, UIA-UAM, 2010, pp. 155 y 162. 
27. A esta lista se le llamó «inventario GaWC» debido a que formaba una de las plataformas para la investigación futura de los miembros que quisiera adherirse al GaWC. Este inventario era la recopilación de información de los cuatros sectores de servicios analizados en 122 ciudades $^{47}$, y que al momento ya se estudian 707, y con ello poder concebir la «conformación de la red mundial de ciudades que se enlazan por índices de conectividad diferenciales, y así construir la red mundial» ${ }^{48}$. Mediante una taxonomía el estudio clasificó según la puntuación de cada ciudad en tres diferentes grupos: Alfa, Beta y/o Gamma $^{49}$. De este modo, esa red puede ser entendida de la siguiente manera «una trama de puntos interconectados, una multitud de redes de negocios que se superponen entre sí y da lugar a ciudades cosmopolitas debido a la mezcla de agentes comerciales. Por tanto, la red de ciudades es resultado del surgimiento de corporaciones multinacionales y firmas avanzadas que proveen servicios globales» ${ }^{50}$.

28. Dentro las conclusiones indican que el interés del inventario se encontraba en los niveles más bajos de cityness en el mundo, lo que podría proporcionar una geografía mundial de los centros globales de servicios ${ }^{51}$, «ya que muestra una concentración regional bastante notable actuando en los principales escenarios de globalización, a saber, en Norteamérica, en Europa Occidental y en Asia-Pacífico, siendo una expresión concreta de la globalización desigual» ${ }^{52}$ donde «las ciudades mundiales o globales son los centros de control y los lugares estratégicos, en un primer momento de la nueva división internacional del trabajo, posteriormente de la globalización» ${ }^{53}$, y por tanto, «la red de ciudades globales es el esqueleto de la economía global» ${ }^{54}$.

29. Este estudio se ha realizado desde el 2000 a la actualidad (2018) el cual ha incluido más ciudades y otros niveles de estudio. Peter J. Taylor y sus

47 Beaverstock, J. V. et al., op. cit., nota 40, p. 454.

48 Alfie, M., Azuara, I., Bueno, C., Pérez, M. y Tamayo, S. (coords.), Sistema Mundial y nuevas geografías, Ciudad de México, UIA-UAM, 2010, p. 15.

49 El grupo GaWC reunió datos de redes de oficinas (ss.ice networks) de un total de cien empresas globales en los sectores de publicidad, banca, servicios jurídicos y contables. Así, este análisis de la red de ciudades mundiales se basa en investigaciones sobre numerosas empresas de servicios globalmente activas (global service firms). «La ventaja principal del inventario GaWC es la gran cantidad de datos cuantitativos con la posibilidad de ser comparables dando así la identificación de ciudades mundiales una base empírica sólida», BEAVERSTOCK, J. V. et al., op. cit., nota 40, p. 457. Al 2018, los resultados se basan en las redes de oficinas de 175 empresas de servicios avanzados en 707 ciudades, https://www. lboro.ac.uk/gawc/world2018.html.

50 AlfIE, M. et al., op. cit., nota 48, p. 24.

51 La cityness es concepto clave para esta metodología, ya que «remite a un grupo de procesos entrelazados a través de los cuales las ciudades crean un ambiente favorable que posibilita su expansión económica. Lo he dominado porque solo en las concentraciones de poder económico que se conforman en las ciudades se generan estos procesos, de los cuales cuatro son clave [formación del centro, formación regional (global city-region), formación de la red de ciudades (world city network) y formación de zonas urbanas marginales (city-yoke formation)]». TAYLOR, P. J., op. cit., nota 46, p. 152.

52 Beaverstock, J. V. et al., op. cit., nota 40, p. 457.

53 TAYLOR, P. J. et al., op. cit., nota 13, p. 231.

54 TaYlor, P. J., "Leading World Cities: Empirical Evaluations of Urban Nodes in Multiple Networks», Urban Studies, vol. 42, 2005, núm. 9, pp. 1593-1608. 
colaboradores consideran que se está reconfigurando «un nuevo mapa del mundo derivado de las conexiones entre ciudades se presenta como complemento al mapa mundial tradicional de los Estados. Bajo las condiciones de la globalización contemporánea, las ciudades mundiales se han convertido en los centros de servicio global» ${ }^{55}$. «En cierta forma el mapa de las ciudades mundiales está sustituyendo al mapa político mundial en cuanto a estructura espacial crucial de la política mundial [...]. Da una imagen muy distinta del mundo de la humanidad: los puntos representan nodos de un espacio mundial de flujos» ${ }^{56}$.

30. Como se observa la red de ciudades mundiales del GaWC proporciona diversas formas de entender el papel de las ciudades en el espacio global. Este análisis ofrece un gran espectro de posibles estudios, ya que se pueden elaborar trabajos comparados sobre las similitudes y diferencias internas dentro de las ciudades y sus relaciones entre ellas ${ }^{57}$. Desde el aspecto cuantitativo se puede llevar a cabo análisis estadísticos con instrumentos propios ${ }^{58}$, o cartografías y mapeos (mapping) de las relaciones de las empresas de servicios entre la red de ciudades mundiales ${ }^{59}$. También permite realizar exploraciones ${ }^{60}$, así como ofrecer nuevos estudios sobre el análisis de redes ${ }^{61}$ y la forma de concebir el Sistema Internacional ${ }^{62}$. Para Peter J. Taylor «la red de ciudades define la parte medular de la economía mundial, es decir, el espacio de los flujos entre ciudades, no el espacio de lugares que establecen los Estados» ${ }^{63}$.

55 TaYlor, P. J., Hoyler, M., Walker, D. R. F. y Szegner, M. J., «A New Mapping of the World for the New Millennium», The Geographical Journal, vol. 167, 2001, núm. 3, p. 213.

56 TAYLOR, P. J. y FlinT, C., op. cit., nota 38, p. 360.

57 Sobre las metodologías que se pueden implementar para medir las relaciones entre ciudades en estudios comparados se recomienda: Beaverstock, J. V., Smith, R. G., Taylor, P. J., Walker, D. R. F. y LORIMER, H., "Globalization and world cities: some measurement methodologies», Applied Geography, 2000, núm. 20, pp. 43-63.

58 TaYlor, P. J. y Walker, D. R. F., «World Cities: A First Multivariate Analysis of their Service Complexes», Urban Studies, vol. 38, 2001, núm. 1, pp. 23-47; Bassens, D., Huang, J., Witlox, F., Shen, W., Yang, X., Derudder, B., Taylor, P., Ni, P., De Vos, A., Hoyler, M. y Hanssens, H., «Pathways of Change: Shifting Connectivities in the World City Network, 2000-2008», Urban Studies, vol. 47, 2010, núm. 9, pp. 1861-1877.

59 TAYLOR, P. J. et al., op. cit., nota 55.

60 Sobre este punto revisar la trilogía de artículos sobre el tema: TAYLOR, P. J., «Specification of the world city network», Geographical Analysis, vol. 33, 2001, núm. 2, pp. 181-194; TAYLOR, P. J., CATALANO, G. y WALKER, D. R. F., "Measurement of the world city network», Urban Studies, vol. 39, 2002, núm. 13, pp. 2367-2376; TAYlor, P. J., Catalano, G. y Walker, D. R. F., «Exploratory analysis of the world city network», Urban Studies, vol. 39, 2002, núm. 13, pp. 2377-2394.

61 Sobre los distintos modelos que pueden ser adoptados (rankings, índices, o mediciones de la estructura de la red en general), véase TAYLOR, P. J., «Parallel Paths to Understanding Global Intercity Relations», American Journal of Sociology, vol. 112, 2006, núm. 3, pp. 881-894.

${ }^{62}$ TAYLOR, P. J., «New political geographies: Global civil society and global governance through world city networks», Political Geography, 2005, núm. 24, pp. 703-730; TAYLOR, P. J., op. cit., nota 11, pp. 201-216.

63 Alfie, M. et al., op. cit., nota 48, p. 25. 


\section{LA INFLUENCIA DE LA CIUDAD GLOBAL EN LAS RRII}

31. Para Neil Brenner, la formación de la ciudad global y el re-escalamiento del Estado son momentos dialécticamente entrelazados de una misma dinámica de reestructuración del capitalismo global ${ }^{64}$. Para Peter J. Taylor y el GaWC durante los ochenta y principios de los noventa «el estudio de las relaciones Ciudad/Estado fueron revisadas como una preocupación entre gobiernos Centrales/Locales. En específico desde dos visiones: 1) la gobernabilidad local y la transferencia de responsabilidades del Estado a la ciudad (descentralización), y 2) las ciudades como ganadoras en la globalización económica, es decir, el Estado como contenedor al parecer estaba dejando escapar a las ciudades» ${ }^{65}$. Debido a que «los Estados no son eternos [...] son construcciones históricas que pueden llegar a ser deconstrucciones históricas, que es el espíritu de la desaparición del estado. Y especulo sobre la futilidad de la territorialidad ya que creo que el estado como contenedor está condenado» ${ }^{66}$.

32. Con base en ello, y asumiendo el espacio de los flujos (spaces of flows) definido por Manuel Castells en la Sociedad Red permiten la conformación de la red de ciudades (city-network formation), «en la que las prácticas crean una división espacial del trabajo que corresponde al espacio de los lugares ${ }^{67}$. A saber:

«Desde el enfoque urbanocéntrico (city-centric). Esta perspectiva considera que la producción de tecnología de punta y los altos salarios conforman un proceso económico en las ciudades que genera zonas centrales (core-making) haciendo posible la configuración de la red de ciudades (city network). El poder que ejercen determinadas prácticas de ciudad (city practices) para modelar las economías según sus propias necesidades, conforma espacios dependientes en los que la producción con tecnología obsoleta y bajos salarios va configurando una periferia [...]. Este enfoque no niega la importancia del poder económico del Estado, sino que se plantea como una cuestión empírica y no como una conjetura. Este poder no genera expansión económica, pero puede facilitarla a través de sus ciudades» ${ }^{6}$.

33. Para Simon Curtis «detrás de la obra [de P. J. Taylor] está la convicción ontológica que las ciudades no deben ser vistos simplemente como lugares limitados - autocontenidos-, sino como procesos continuos de flujos de distinta índole. Esta posibilidad ontológica es una de las rutas de la vinculación de los estudios de las ciudades globales y la teoría de RRII» ${ }^{69}$. Al mismo

\footnotetext{
64 BRENNER, N., "Global cities, "glocal” states: global city formation and state territorial restructuring in contemporary Europe», Review of International Political Economy, vol. 5, 1998, núm. 1, pp. 1-37.

65 TAYLOR, P. J., op. cit., nota 27, p. 134.

${ }^{66}$ TAYLOR, P. J., "The state as container: territoriality in the modern world-system», Progress in Human Geography, vol. 18, 1994, núm. 2, pp. 151-162, p. 161.

67 TAYLOR, P. J., op. cit., nota 46, p. 152.

68 Ibid., pp. 151 y 166.

69 CurTIS, S., "Global Cities and the Transformation of the International System», Review of International Studies, vol. 37, 2010, núm. 4, p. 10.
} 
tiempo, «ya no pueden contener el proceso de acumulación de capital y la urbanización dentro de sus fronteras. Se convierten tanto en cómplices de este re-escalamiento y a su vez están más limitados por ello, así las ciudades globales y sus regiones surgen como el territorio fundamental de la globalización económica» ${ }^{70}$. En otras palabras:

«Hoy en día es posible que las ciudades mundiales estén empezando a alcanzar algunas formas nuevas de independencia respecto a los Estados territoriales, lo que las convierte en algo muy relevante para nuestra geografía política (TAYLOR, 1995). Con ello no queremos decir que los Estados territoriales están a punto de desaparecer, sino que las ciudades mundiales se están convirtiendo en un nuevo locus de poder e interactuarán con los Estados de forma distinta ${ }^{71}$.

34. Desde otra perspectiva más crítica, ya no hay «un centro de gravedad histórico que defina la suerte universal. Hoy se registran multitud de centros de gravedad, es decir, las ciudades. Pero ¿todas? No necesariamente. Ser un centro de gravedad, por simple y elemental que ello sea, requiere de un cierto grado de fungibilidad, de capacidad para transformar cualitativamente recursos y conductas políticas, financieras y culturales, de tal forma que la condición original se vea alterada sensiblemente» ${ }^{72}$. Para Gerardo del Cerro, «tenemos, por tanto, ciudades inscritas en redes que funcionan como nodos en la producción y reproducción de tales redes y de la materia, energía, capital e información que transmiten. Si la globalización es una red, las ciudades son también redes de relaciones, estructuras y territorios. Y en este contexto, en lugar de considerar la agencia del individuo aislado, lo que proponemos son las prácticas de los actores-en-redes ${ }^{73}$.

35. Es en este punto donde la agencia de las ciudades (mundiales y/o globales) a través de sus redes comienza a ser vista como central para entender su influencia actual sobre otros actores. Considerando los siguientes puntos:

«La agencia opera de forma diferente entre lugares e incluso de forma diferente dentro del mismo lugar en tiempos diferentes. [...] Agencia y estructura pueden verse así como un todo analítico, una unidad integrada de procesos reticulares espacio-temporales constituida por nodos y flujos.

La noción de red nos lleva por encima de las distinciones tradicionales en ciencias sociales entre micro y macro procesos [...]. En lugar de tener que escoger entre una perspectiva local y una global, la noción de red nos permite pensar la globalización como un proceso continuamente localizado.

En vez de oponer la agencia a la estructura, simplemente observamos cómo un elemento dado se convierte en relevante mediante el número de conexiones de que forma parte y cómo pierde tal relevancia al perder sus conexiones ${ }^{74}$ (CERRo, 2004: 209).

\footnotetext{
70 CurTis, S., op. cit., nota 69, p. 18.

71 TaYlor, P. J. y Flint, C., op. cit., nota 38, p. 360.

72 TorriJos, V., op. cit., nota 24, p. 359.

73 Del Cerro, G., "Ciudades y globalización: un enfoque teórico», Revista Española de Sociología, 2004, núm. 4, pp. 199-218, esp. p. 209.

${ }^{74}$ Del Cerro, G., op. cit., nota 73, p. 209.
} 
36. No es hasta principios de esta nueva década (2010-2019) cuando se presenta el auge en los estudios teóricos-conceptuales sobre las ciudades y las RRII. La mayoría de ellos, con el objetivo en común de entender la interacción entre la gobernanza global y las ciudades (globales), mientras que otros se han centrado en aspectos sobre la importancia de la identidad y su influencia a nivel exterior ${ }^{75}$ así como el diseño de una política pública de internacionalización desde el gobierno central para actuar de manera paradiplomática.

37. En el caso específico del estudio de las Ciudades Globales y las RRII, una de las grandes justificaciones para la adopción de esta perspectiva teórica a la disciplina, y como bien los señala S. Curtis, es que las diferencias entre los teóricos de ciudades globales y la nueva generación de estudiosos en las RRII no son tan grandes. Ya que este tipo de ciudades al igual que los Estados son consideradas como un conjunto de procesos más que entidades limitadas, así que las RRII actuales tendrían que revisar cómo se relacionan y organizan los componentes del actual Sistema Internacional, los vínculos y nodos, y su persistencia y/o transformación a través del tiempo ${ }^{76}$.

38. Además del GaWC y su análisis sobre la formación de la red de ciudades mundiales (International Handbook of Globalization and World Cities del 2012 editado por Ben Derudder, Michael Hoyler, Peter J. Taylor y Frank Witlox); los principales textos identificados son: Global Cities and Global Order de Simon Curtis (2017). Así como los que pertenecen a distintas colecciones de Routledge:

Cities and Global Governance: New Sites for International Relations editado por Mark Amen, Patricia L. McCarney, Noah J. Toly, Klaus Segbers (2011); Global Cities, Governance and Diplomacy. The Urban Link de Michele Acuto (2013); Cities, Networks, and Global Environmental Governance. Spaces of Innovation, Places of Leadership de Sofie Bouteligier (2013); The Power of Cities in International Relations de Simon Curtis (2014); The Urban Climate Challenge. Rethinking the Role of Cities in the Global Climate Regime, editado por Craig Johnson, Noah Toly, Heike Schroeder (2015); Global Cities and Climate Change. The Translocal Relations of Environmental Governance de Taedong Lee (2015); The Global City 2.0 from Strategic Site to Global Actor de Kristin Ljungkvist (2016); Greening Post-Industrial Cities. Growth, Equity, and Environmental Governance de Corina McKendry (2017); The Globalisation of Urban Governance. Legal Perspectives on Sustainable Development Goal 11 editado por Helmut Philipp Aust y Anél du Plessis (2018); The City as a Global Political Actor editado por Stijn Oosterlynck, Luce Beeckmans, David Bassens, Ben Derudder, Barbara Segaert, Luc Braeckmans (2018).

39. Si bien estudian el mismo fenómeno, la importancia de las ciudades y sus redes en la transformación del sistema internacional, su método de investigación, así como su enfoque teórico para analizar tal dinámica, son diferentes. Por un lado, M. Amen et al., y S. Bouteligier, se basan en las teorías de

75 Lara, R. F. y Cerqueira, O., «Las Ciudades en la Gobernanza Global Multinivel: Una Aproximación Teórica», Revista Si Somos Americanos, 2017, núm. 17, pp. 43-65, esp. p. 60.

${ }^{76}$ CuRTIS, S., op. cit., nota 69, p. 16. 
la Gobernanza Global y la Sociedad Red, mientras que M. Acuto y S. Curtis, en la Teoría del Ensamble y el Actor-Red.

\section{LA CIUDAD GLOBAL Y LAS RRII DESDE LA FORMACIÓN DE LA RED DE CIUDADES MUNDIALES}

40. En un trabajo posterior, Taylor (2005) Leading World Cities: Empirical Evaluations of Urban Nodes in Multiple Networks redefine y re-categoriza en su taxonomía las principales «ciudades en la globalización» con relación a la localización de las sedes centrales de las empresas transnacionales, las agencias de las Naciones Unidas (ONU) y las Organizaciones No Gubernamentales (ONG). Prefiere el término de ciudades en la globalización que ciudades globales, ya que parte del supuesto que «la globalización tiene lugar en las ciudades y las ciudades personifican y reflejan la misma globalización» ${ }^{77}$. Véase la Tabla 3 que ejemplifica dicha dinámica.

41. Existen ciudades que tienen distintas formas de poder, lo cual las posiciona jerárquicamente en un lugar más alto en esta red mundial de ciudades. Esta jerarquía debe ser entendida de la siguiente manera: «las relaciones dentro de la red son las que definen la jerarquía, es decir, en la red de ciudades mundiales todas las ciudades son iguales, pero algunas son más iguales que otras. Pero los diferenciales de poder en la red no son fáciles de distinguir ${ }^{78}$. En el estudio de 2002, Diversity and power in the world city network, P. Taylor, D. Walker, G. Catalano y M. Hoyler identifican a las ciudades más poderosas en la red de ciudades mundiales, señalando que con la diversidad de ciudades mundiales, en cuanto "a rangos, roles, nichos y posiciones dentro de la red se puede entender las fuertes implicaciones para los gobiernos municipales y el sector privado local, y las maniobras que deben de implementar dentro de sus ciudades para hacer frente a las convulsionada globalización» ${ }^{79}$.

42. A través de una taxonomía: a) El poder como capacidad a través de las conexiones: 1) ciudades del mundo altamente conectadas; 2) conectividad de los centros financieros internacionales. $b$ ) El poder como centros de dominación y mando: 1) centros dominantes; 2) centros de comando global; 3) centros de mando regionales. c) Poder a través de la red: los lugares con aspiraciones (the place to be): 1) puertas de entrada de alta conectividad; 2 ) puertas de entrada para los mercados emergentes ${ }^{80}$. Es por esta dinámica, que las redes de ciudades, "son unidades que se necesitan y complementan, no existe, para Taylor, posibilidad de competencia entre ellas, pues se crea una relación horizontal sin jerarquías ni privilegios» ${ }^{81}$.

\footnotetext{
77 ShORT y KIM, 1999, citados por TAYLOR, P. J., op. cit., nota 22, p. 1605.

78 TAYLOR, P. J., et al., op. cit., nota 13, p. 239.

79 Ibid., nota 13 , p. 240.

80 Ibid., nota 13.

81 Alfie, M., "Ciudad global: límite analítico en la construcción del espacio urbano», en ALFIE, M. et al., op. cit., nota 48, p. 179.
} 
Tabla 3. Taxonomía de las principales ciudades en la globalización

\begin{tabular}{|c|c|c|c|}
\hline \multirow{5}{*}{$\begin{array}{l}\text { Ciudades } \\
\text { Globales }\end{array}$} & \multirow{3}{*}{$\begin{array}{c}\text { Funcionalmente } \\
\text { Integradas / Bien } \\
\text { situadas }\end{array}$} & $\begin{array}{l}\text { Con amplia } \\
\text { contribución }\end{array}$ & Londres y Nueva York \\
\hline & & $\begin{array}{l}\text { Con menor } \\
\text { contribución, y con } \\
\text { fuerza cultural }\end{array}$ & $\begin{array}{c}\text { Los Ángeles, París } \\
\text { y San Francisco }\end{array}$ \\
\hline & & $\begin{array}{c}\text { Incipientes ciudades } \\
\text { globales }\end{array}$ & $\begin{array}{l}\text { Ámsterdam, Boston, } \\
\text { Chicago, Madrid, Milán, } \\
\text { Moscú, Toronto }\end{array}$ \\
\hline & \multirow{2}{*}{$\begin{array}{l}\text { Nichos globales } \\
\text { de ciudades / Con- } \\
\text { tribuciones globales } \\
\text { especializadas }\end{array}$} & $\begin{array}{l}\text { Con contribución } \\
\text { global especializada } \\
\text { financiera }\end{array}$ & $\begin{array}{c}\text { Hong Kong, Singapur } \\
\text { y Tokio }\end{array}$ \\
\hline & & $\begin{array}{l}\text { Con contribución } \\
\text { global especializada } \\
\text { política y social }\end{array}$ & $\begin{array}{c}\text { Bruselas, Ginebra } \\
\text { y Washington }\end{array}$ \\
\hline \multirow{5}{*}{$\begin{array}{l}\text { Ciudades } \\
\text { Mundiales }\end{array}$} & \multirow{3}{*}{$\begin{array}{c}\text { Subredes } \\
\text { articuladoras } \\
\text { de ciudades }\end{array}$} & $\begin{array}{l}\text { Articuladoras } \\
\text { culturales }\end{array}$ & $\begin{array}{l}\text { Berlín, Copenhague, } \\
\text { Melbourne, Múnich, Oslo, } \\
\text { Roma, Estocolmo }\end{array}$ \\
\hline & & $\begin{array}{l}\text { Articuladoras } \\
\text { políticas }\end{array}$ & Bangkok, Viena, Pekín \\
\hline & & $\begin{array}{l}\text { Articuladoras } \\
\text { sociales }\end{array}$ & Manila, Nairobi, Ottawa \\
\hline & \multirow[b]{2}{*}{$\begin{array}{l}\text { Ciudades líderes } \\
\text { a lo largo del mundo }\end{array}$} & $\begin{array}{l}\text { Contribución } \\
\text { principalmente } \\
\text { económica }\end{array}$ & $\begin{array}{l}\text { Frankfurt, Miami, Múnich, } \\
\text { Osaka, Singapur, Sídney, } \\
\text { Zúrich }\end{array}$ \\
\hline & & $\begin{array}{l}\text { Contribución } \\
\text { principalmente no } \\
\text { económica }\end{array}$ & $\begin{array}{c}\text { Abijan, Addis Abeba, } \\
\text { Atlanta, Basilea, Barcelona, } \\
\text { El Cairo, Denver, Harare, } \\
\text { Lyon, Manila, Ciudad de } \\
\text { México, Mumbai, Nueva } \\
\text { Delhi, Shanghái }\end{array}$ \\
\hline
\end{tabular}

Fuente: elaboración propia con datos de TAYLOR, P. J., 2005

43. El poder dentro de la red de ciudades mundiales «puede ser tanto una capacidad expresada en tendencias jerárquicas y como un medio colectivo expresado en las diferencias de poder a través de posición en la red ${ }^{82}$. «A lo largo de la historia las ciudades más importantes han sido los centros de poder del Estado, esto no ha cambiado mucho, ya que en el inventario de las ciudades mundiales o globales sigue dominado por las ciudades capitales. [...] sí se revisan las esferas de influencia regional de las ciudades mundiales

${ }^{82}$ TAYLOR, P. J. et al., op. cit., nota 13, p. 233. 
habría que cambiar ciertas ideas pasadas» ${ }^{83}$ véase Gráfico 1 . Por ejemplo, Singapur sirve de sede principal donde se toman y se ejecutan las decisiones de inversión respecto a todos los países del Sudeste Asiático. Miami desempeña un papel parecido para los Estados caribeños e incluso para América Latina. La influencia de Londres, Nueva York y Tokio tienen un alcance aún más transnacional ${ }^{84}$.

Gráfico 1. Esferas de Influencia Regional de las Ciudades Mundiales según Peter Taylor, 2000

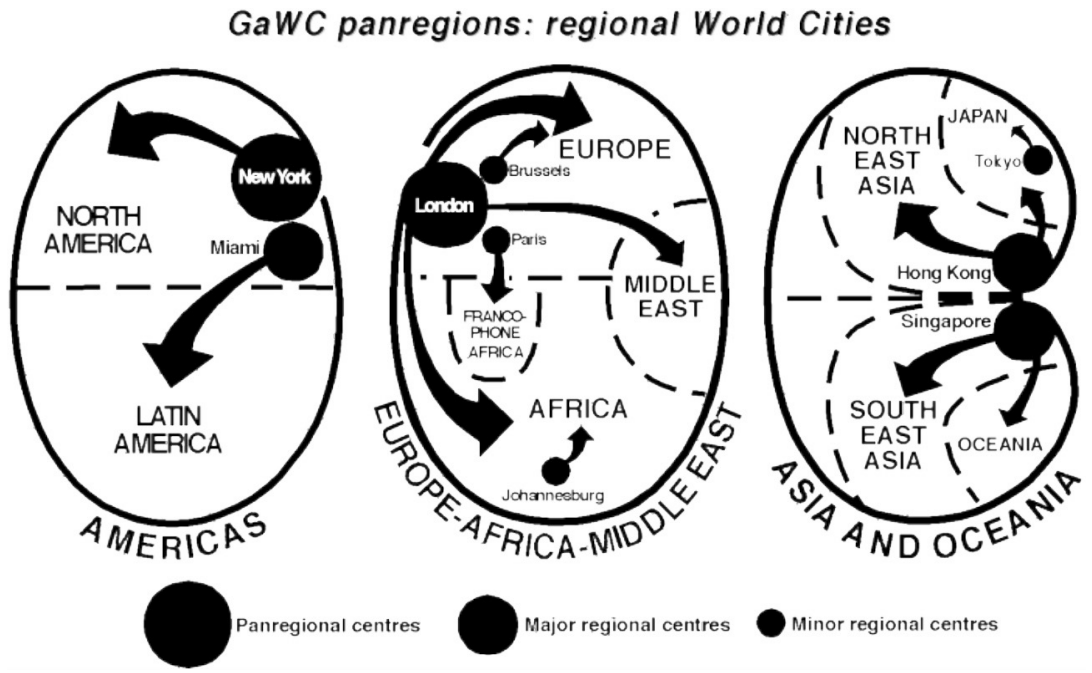

Fuente: TAYLOR, P. J., 2000.

44. En sus últimos estudios centrados en las RRII, Peter J. Taylor identifica las redes que modifican el actuar de las ciudades mundiales en relación, por ejemplo a los Estados (mundo Westfaliano), la gobernanza global y la sociedad civil global, con base en su modelo de la red entrelazada de ciudades mundiales. En su trabajo de 2005, identifica tres redes de ciudades, las cuales podrían considerarse como las nuevas representaciones del espacio de los flujos:

«1. Red de ciudades inter-estatal compuesta por las embajadas, consulados y demás departamentos de Estado como los responsables (agentes, nodos, network-makers) de la red. Que privilegia una clase específica de ciudades: las ciudades capitales. Desde la perspectiva de la conformación de la red de ciudades mundiales, son "los centros políticos de mando y control", la sede central de las instituciones que toman las decisiones, "el brazo" de los gobiernos estatales en materia de asuntos exteriores [...]. Esta red abarca más allá de las capitales,

83 TAYLOR, P. J., «World cities and territorial states under conditions of contemporary globalization», Political Geography, 2000, núm. 19, pp. 5-32, esp. pp. 6 y 23.

${ }^{84}$ TAYlor, P. J. y Flint, C., op. cit., nota 38, p. 360. 
ya que existe personal diplomático que es enviado a misiones en otras ciudades no capitales ${ }^{85}$.

2. Red de ciudades supra-estatal representada por las agencias de las ONU como las tomadoras de decisiones. La creación de las ONU al final de la Segunda Guerra Mundial fue un proceso inter-estatal con implicaciones supraestatales. A pesar de ser la institución arquetípica interestatal por ser un producto de la guerra y la paz [...] sus prácticas atienden un amplio espectro de actividades que la han llevado a tener una presencia supraestatal en el espacio de los flujos de política mundial. Tomando la idea de Rosenau sobre "el potencial servicio global de las ONU" (1992: 69), sus agencias operan a través de las ciudades para crear sus redes [...] cada agencia tiene diferentes grados de presencia en las ciudades [...] el número de ciudades que aparecen en las subredes supraestatales es muy pequeña lo que implica grados más selectivos de localización [...]. Esto indica que la red supraestatal tiene tendencias jerárquicas muy fuertes ${ }^{86}$.

3. Red de ciudades trans-estatal definida por las ONG como los actores centrales para la formación de esta red. Con la conformación de la sociedad civil global. Este nuevo mundo social está constituido por redes, coaliciones, alianzas y movimientos sociales, siendo las ONG las que comúnmente se asumen como los operadores clave de la red» ${ }^{87}$.

45. Esta propuesta ha sido criticada, en lo relativo a la conformación de varias redes de ciudades que hospedan las agencias de las ONU (supra-state city network) y las sedes de las ONG (trans-state city network). Mónica Salomón indica que «su representación de la estructura de la gobernanza global a través de los flujos que conectan las ciudades es de poca utilidad para la comprensión del fenómeno. Por varias razones: 1) cuando se habla de la gobernanza global desde una perspectiva de las ciudades, no es posible ignorar el papel de los gobiernos locales como agentes, creadores o responsables de la red, algo que hace Taylor. [...] 2) en su definición de las redes de gobernanza global y sociedad civil global, no presta la atención necesaria a la relación de la ciudad como espacio de los lugares y como un espacio de flujos» ${ }^{88}$.

46. En 2015, desde la perspectiva de la Geografía Política, el texto International Handbook Of Globalization And World Cities, de Ben Derudder, Michael Hoyler, Peter J. Taylor y Frank Witlox (eds.), es el último de un sinfín de publicaciones provenientes del GaWC ${ }^{89}$. Este manual-handbook, tiene como propósito presentar el estado de la cuestión actual de las ciudades mundiales, desde sus relaciones exteriores (globalización), así como de sus estructuras internas (urbanización) y como se entrelazan en la ciudad mundial. Para Tay-

85 TAYLOR, P. J., op. cit., nota 62, pp. 711-712.

${ }^{86}$ Ibid., pp. 714-715.

87 Ibid., p. 716.

88 Salomón, M., "Local Governments as Foreign Policy Actors and Global Cities Network-Makers: the Cases of Barcelona and Porto Alegre», Paper presented at the 49th annual Convention of the International Studies Association, San Francisco, California, 2008, marzo, pp. 4 y 10.

${ }^{89}$ Los textos primigenios de esta magnitud son: KNOX, P. L. y TAYLOR, P. J., World Cities in a WorldSystem, Cambridge, Cambridge University Press, 1995; TAYlor, P. J., Derudder, B., Saey, P. y Witlox, F. (eds.), Cities in Globalization: Practices, Policies and Theories (Questioning Cities), Londres, Routledge, 2007. 
lor «las ciudades mundiales o globales son la manifestación geográfica más llamativa de los procesos trans-estatales contemporáneos» ${ }^{90}$.

\section{LA CIUDAD GLOBAL Y LAS RRII DESDE LAS TEORÍAS DE LA GOBERNANZA GLOBAL}

47. El texto de M. Amen et al., Cities and Global Governance: New Sites for International Relations, señala en su introducción que las ciudades «son cada vez más decisivas en la gobernanza global» ${ }^{91}$. Los editores de la obra afirman que su objetivo es el de "promover la innovación en la teoría de las RRII mediante estudios de casos que amplíen la base teórica sobre el papel formal e informal de las entidades subnacionales como actores políticos en la gobernanza global» ${ }^{92}$. M. Acuto señala que "a pesar de las aspiraciones declaradas ${ }^{93}$ y el enfoque multidisciplinar del libro, en términos teóricos solo es un bosquejo superficial de la relación entre la ciudad global y las RRII» ${ }^{94}$. Respecto a esta crítica, Mark Chou indica que el libro plantea que el Estadonación ya no puede ser considerado como el único, e incluso, el actor clave en el ámbito internacional, y que en tal caso le falta proponer el siguiente paso:

«Después de haber inquietado al Estado-nación de esta manera, el libro no da el siguiente paso, previendo que la ciudad — junto con el Estado-nación- es también un actor en la política mundial. El hecho de no haberlo hecho, significa que las ciudades sigan siendo simplemente "nodos" y "hubs" globales, algo que en su mejor momento solo podría aumentar y facilitar las relaciones internacionales y las transacciones globales» ${ }^{95}$.

48. Sofie Bouteligier, en su libro Cities, Networks, and Global Environmental Governance. Spaces of Innovation, Places of Leadership, identifica el activismo global de las ciudades en la cuestión medioambiental a través del análisis de las redes de ciudades (Metrópolis y el C40), basándose en el marco teórico de la sociedad en red y las ciudades globales desde una perspectiva de la ecología mundial. El surgimiento de estas redes permite entender el nuevo activismo ambiental global de las ciudades (A Networked Urban World as Vehicle for Environmental Sustainability). En un artículo previo detecta dos tipos de redes de ciudades y sus funciones centrales en la gobernanza global ${ }^{96}$ :

90 TAYLOR, P. J., op. cit., nota 83, p. 6.

91 Amen, M. M., McCarney, P. L., Toly, N. J. y Segbers, K. (eds.), Cities and global governance: new sites for international relations, Farnham, Ashgate Publishing, 2011, p. 3.

92 AMEN, M. M. et al., op. cit., nota 91, p. 4.

93 "The purpose of these studies is to redress the under representation of cities and sub-national regions as sites of governance or partners in global governance in much of the disciplinary literature produced by scholars in international relations, environmental and regional studies, and foreign policy analysis». AMEN, M. M. et al., op. cit., nota 91, p. 4-5.

94 AcuTo, M., Global Cities, Governance and Diplomacy, the Urban Link, Londres, Routledge, 2013, p. 7.

95 CHOU, M., "The subject of analysis: global cities and international relations», Global Change, Peace \& Security, vol. 24, 2012, núm. 2, pp. 305-307, esp. p. 306.

96 Véase Bouteligier, S., "Global cities and Networks of Global Environmental Governance», $P a$ per presented at the 49th annual Convention of the International Studies Association, San Francisco, California, 2008, marzo. 
«Se establecen con el objetivo de hacer frente a los desafíos urbanos de manera más eficiente. Las ciudades cooperan entre ellas como actores intercambiando experiencias (expertise), buenas prácticas (best practices) y conocimiento (know how) Además pueden ser partícipes de estas redes otros actores públicos y privados, los cuales realizan asistencia técnica o financiera mediante acuerdos híbridos (hybrid arrangements) ${ }^{97}$.

Se establecen por la localización estratégica. Aquí cumplen el rol de ser un sitio estratégico como un entorno urbano de interacción. Aquí, el gobierno local no tiene importancia, ya que la ciudad es la que se convierte en el lugar de reunión (conocimiento, infraestructura e instituciones)» ${ }^{98}$.

49. En esta segunda función, «las ciudades que juegan ese rol estratégico en las redes globales son identificadas como ciudades mundiales o globales [...] donde estas ciudades o nodos urbanos no existen por sí mismas, sino que adquieren su importancia desde la misma red. Aquí la unidad de análisis, es la red no la ciudad, debido a ello el enfoque relacional es necesario para su estudio» ${ }^{99}$. Mónica Salomón comienza a revisar perspectivas de los estudios urbanos y de la Geografía Política con la intención de complementarlos con las RRII. En varios de sus trabajos, el actor principal es el gobierno local en la creación de ambas redes transnacionales. Para ella, "las actividades de las redes transnacionales dirigidas por los propios gobiernos locales se han destacado en repetidas ocasiones como elementos esenciales de la gobernanza global y, en menor medida, en la sociedad civil global» ${ }^{100}$.

50. En lo que respecta al estudio de las dos formas de redes transnacionales de ciudades: 1) redes constituidas formalmente, y 2) redes globales. Robert Kissack señala que «la jerarquía de ciudades pretende identificar aquellas que se han convertido en los actores más importantes en la política global. La importancia puede medirse en dos formas: mediante 1) el número de redes cooperativas formales; o a través de 2) la cualificación y cuantificación de la conectividad entre ciudades ${ }^{101}[\ldots]$ "son los nodos organizativos fundamentales en múltiples redes globales de flujos económicos, sociales, demográficos e informativos" " ${ }^{102}$. Salomón identifica que dentro de las perspectivas que analizan la creación de las mismas hay dos posturas diversas sobre el agente central que fomenta la creación de estas redes:

«Estudios Urbanos incluidos la Geografía Política y la Sociología Urbana. Centrados en los flujos - especialmente económicos- que conectan a las ciudades con el objetivo de establecer una geografía política de la globalización

\footnotetext{
97 Véase Spangaren, G., Mol, A. P. J. y Buttel, F. H., Governing Environmental Flows: Global Challenges to Social Theory, Boston, MIT Press, 2006, pp. 15-16.

98 Bouteligier, S., "Cities and Global Environmental NGOs: Emerging Transnational Urban Networks?», en Amen, M. M., McCarney, P. L., Toly, N. J. y Segbers, K. (eds.), Cities and global governance: new sites for international relations, Farnham, Ashgate Publishing, 2011, p. 153.

99 Bouteligier, S. et al., op. cit., nota 98, pp. 153-154.

100 SAlOMÓN, M., op. cit., nota 88, p. 1.

101 KISSACK, R. "Ciudades y relaciones internacionales», Revista CIDOB d'afers internacionals, 2013, núm. 104, p. 13.

102 Smith, 2005, p. 48, citado en KIsSacK, R., op. cit., nota 101, p. 13.
} 
centrada en las ciudades así como las relaciones de jerarquía y poder entre ellas. En estos estudios, los actores responsables (network-makers) de la generación de flujos reciben menos atención que los propios flujos (económicos, de información o de conocimiento). Por tanto, la red existe si la conectividad entre los nodos es significativa. Independientemente si los responsables de la red están interesados en su formación.

Estudios Políticos incluidos la Ciencia Política, la Sociología Política y las RRII. Lo que normalmente se entiende por redes de ciudades son los esquemas de cooperación voluntaria por parte de los gobiernos locales, estas redes pueden tener diversos grados de institucionalización. Su alcance varía, dependiendo de la orientación así como del número de temas u áreas en las que buscan participar» ${ }^{103}$.

51. Otra autora que ha centrado sus estudios en la importancia de la ciudad dentro de la gobernanza global a través del estudio de redes de ciudades y ciudades globales, así como el estudio de políticas públicas, es Vanessa Marx. Entre sus aportaciones centrales, al igual que Salomón desde la gobernanza, está la importancia de las políticas públicas como precursoras de inserción internacional, entre ellas, la mercadotecnia de ciudad para ser reconocida a nivel internacional ${ }^{104}$. La dinámica actual del Sistema Internacional permite y obliga a las ciudades a crear sus propios mecanismos (políticas públicas) de atracción de talento, capital, turismo, inversión y poblaciones, en general. También les incita a manifestarse ante los demás actores internacionales como actores políticos, económicos y culturales, y a presentarse como ciudades resilientes ante los distintos cambios del entorno global.

52. Desde la glocalización, «la ciudad, como puente entre el territorio y la ciudadanía, puede jugar un papel fundamental para determinar una nueva etapa en las relaciones internacionales» ${ }^{105}$.

«A través del concepto de governance, conseguimos identificar un marco teórico adecuado para trabajar el aspecto político de las ciudades en el ámbito internacional. El poder de gobernar y establecer relaciones internacionales ya no pertenece al Estado en exclusiva, sino que se abre así un escenario distinto donde gestionar los asuntos en red y donde poseer una capacidad relacional para saber compartir decisiones abre oportunidades para los poderes locales junto con otros actores. Las ciudades, en tanto que gobiernos de proximidad, tienen la capacidad de relacionarse de forma más próxima con las redes sociales, políticas, culturales y económicas de diversos actores que actúan en el territorio y a la vez en la escena internacional» ${ }^{106}$.

103 SAlOMón, M., op. cit., nota 88, pp. 3.

104 MarX, V., «Las ciudades en la globalización», Arquiteturarevista, vol. 2, 2006, núm. 1, http:// www.redalyc.org/articulo.oa? $i d=193616282004$.

105 MARX, V., "Las ciudades y su inserción política en las relaciones internacionales», en MARTín, M. A. y Oddone, C. N., Las ciudades y los poderes locales en las relaciones internacionales contemporáneas, Granada, UIM, 2010, p. 43.

106 MARX, V., op. cit., nota 105, p. 37. 


\section{LA CIUDAD GLOBAL Y LAS RRII DESDE LAS TEORÍAS DEL ENSAMBLAJE}

53. Los autores que más han escrito sobre las ciudades globales y las RRII son Michele Acuto y Simon Curtis. Siguen el enfoque holístico de la Teoría del Actor-Red (Actor Network Theory, ANT) desde la perspectiva de la Sociología de la traducción u Ontología del Actante-Rizoma de Bruno Latour, Michael Callon y John Law que tienen como objetivo re-ensamblar lo social ${ }^{107}$. Por un lado, con la intención de incluir el estudio de las ciudades globales en las RRII y cómo estas forman colectivos sociales que impactan en la política mundial — como actores-y la gobernanza global — como actantes-; y por el otro, con relación a las transformaciones históricas, la Teoría del Ensamble, "permite a los especialistas rastrear cómo se desmontan - $\mathrm{O}$ desensamblan- y son reconstruidas las capacidades e instituciones de una era histórica, y como estas producen nuevas capacidades e instituciones» ${ }^{108}$ en este caso durante el fenómeno histórico de la globalización.

54. Entre los argumentos para razonar el estudio de las ciudades globales desde las RRII, por parte de Michele Acuto y Simon Curtis la justificación más importante para entender el estudio de las ciudades (globales) desde las RRII es la revisión de John G. Ruggie ${ }^{109}$, a saber:

«Para disociar la noción de territorialidad que subyace al Estado moderno, Curtis se apoya en los trabajos de Ruggie sobre territorialidad, soberanía y la construcción de lo internacional. Para él, en la época medieval podían coexistir múltiples fuentes de autoridad, porque su potestad se extendía más sobre los individuos con múltiples identidades que sobre territorios fijos. [...] Para Rug-

107 Sobre la teoría ANT véase LATOUR, B., Reensamblar lo social. Una introducción a la teoría del actor-red, Buenos Aires, Manantial, 2005. El origen de la teoría del ensamble proviene desde la filosofía de Gilles Deleuze y Manuel Delanda. Retomado por la sociología de Bruno Latour, Michael Callon, John Law y Saskia Sassen. «La teoría de ensamblajes ha sido desarrollada desde la filosofía y política pero también en los estudios de ciencia y tecnología, desde la ANT. Y por ese camino de la sociología de lo tecnológico y del materialismo ha llegado a la ciudad, donde ha servido para hacer muy buenas descripciones y nos ofrece nuevas herramientas de trabajo [...]. Los ensamblajes o articulaciones proponen un desplazamiento de la perspectiva a la ontología. Los ensamblajes son pluridisciplinares, multiescalares o translocales, no reduccionistas, heterogéneos, materialistas (no reificados o imaginados) y procesuales». GISBERT, E., "¿Qué aporta la teoría de ensamblajes a la construcción de la ciudad?», Colaboradores, entrada de blog 29 de julio de 2014, http://colabores.net/2014/07/29/que-aporta-la-teoriade-ensamblajes-a-la-construccion-de-la-ciudad/. Y «es, al mismo tiempo, una teoría sobre el movimiento de montaje o ensamblaje de los elementos de la sociedad que llevan a constituir conjuntos y colectivos». PÉrez, J. M. (2015), "¿Por qué está de moda la teoría del actor-red?», JMPT en Comunicación, entrada de blog 24 de febrero de 2015, http://www.jmpereztornero.eu/2015/02/24/por-que-esta-de-modala-teoria-del-actor-red/.

108 CuRTIS, S., op. cit., nota 69, p. 16.

109 "I update three frameworks opened up by Ruggie in his seminal collection as starting points to think about how the emergence of global cities may be indicative of transformative trends of epochal significance; the relationship of units and structures in international systems, the notion of "territorial unbundling" as it relates to global assemblages, and the socially constructed nature of spatial and temporal structures», CurTIS, S., op. cit., nota 69, p. 12. Véase RugGIE, J., Constructing the World Polity: Essays on International Institutionalisation, Londres, Routledge, 1998. 
gie es plausible que en el futuro existan formas de autoridad política que no se hallen emplazadas en una unidad territorial soberana, como ocurre hoy en día. Según Curtis, la propuesta de Ruggie encaja perfectamente con desarrollos de la sociología de las ciudades globales como el de Sassen» ${ }^{110}$.

55. Simon Curtis en su artículo Global cities and the transformation of the International System sostiene que «cualquier intento de atribuir a las ciudades la misma importancia analítica que los Estados constituye un desafío para las RRII, ya que estas se asientan sobre el presupuesto ontológico de que el Estado soberano opera en un sistema internacional anárquico» ${ }^{111}$. A tal fin, «es imperativo desarrollar bases ontológicas y epistemológicas para entender el papel de las ciudades globales en el sistema internacional» ${ }^{112}$. Su argumento central es: «Las ciudades no van a tomar el lugar de los Estados, pero los cambios en la naturaleza de las ciudades y los Estados en la coyuntura contemporánea forman parte de los mismos procesos de re-escalamiento de la relación entre los espacios local, nacional y global» ${ }^{113}$.

56. Para llegar a esto parte de su trabajo justifica como el «análisis de las ciudades globales proporciona ejemplos concretos de los mecanismos por los cuales la territorialidad se está redimensionando en el periodo tardomoderno, algo que se alinea muy bien con el argumento de Ruggie» "114. Así, «el surgimiento de las ciudades globales es una manifestación de los procesos actuales de transformación que operan en el sistema internacional» ${ }^{115}$.

57. En su libro Global Cities, Governance and Diplomacy. The Urban Link, M. Acuto identifica las grandes limitaciones de la academia de RRII en lo relativo al estudio de las ciudades:

«No ha ideado de manera efectiva marcos teóricos para descubrir fragmentos del urbanismo y/o la geografía que puedan ser traducidos en consideraciones teóricas desde las RRII. Por lo general carece de una apreciación — productiva y progresiva- de la activa participación de las ciudades en la política mundial y su influencia directa que tienen en la gobernanza global. Cuando dicha participación e influencia se ha insinuado, hasta este momento no se han desarrollado análisis sobre los orígenes e impactos de dicha capacidad diplomática» ${ }^{116}$.

58. Para resolver la primera limitación, al implementar la perspectiva sociológica del Actor-Red que está ampliamente difundida en el urbanismo, explica la importancia de estas nuevas posturas. Respecto al segundo punto, asume la agencia de las ciudades globales, concepto acuñado en las disciplinas de la Sociología Urbana y la Geografía Política, para entender sus articuladores principales en la gobernanza global analizadas como «actantes», «actores» $\mathrm{y}$ «red de redes». Para probar la influencia de la ciudad global — the

\footnotetext{
110 KISSACK, R., op. cit., nota 101, p. 14.

111 CurTIS, 2011, citado por KISSACK, R., op. cit., nota 101, p. 14

112 CuRTIS, 2011, citado por AcUTo, M., op. cit., nota 94, p. 7.

113 CuRTIS, S., op. cit., nota 69, p. 23.

114 CURTIS, 2011, citado por KISSACK, R., op. cit., nota 101, p. 14.

115 CuRTIS, S., op. cit., nota 69, p. 23.

116 AcuTo, M., op. cit., nota 94, p. 9.
} 
urban link-, según los postulados del ANT y el re-ensamblaje, analiza el caso del Cities Climate Leadership Group o C40 como el articulador central de la gobernanza global en el tema del cambio climático.

59. Lo más importante de su postura es que discute sobre la agencia de las ciudades globales y sus redes transnacionales, donde el estudio de las ciudades y su agencia desde las RRII pasan por un impasse o ha sido analizadas a través de callejones sin salida (culs de sac): 1) las ciudades no son repúblicas miniatura, y 2) las ciudades no son personas. Para resolver estos problemas de agencia de la ciudad ofrece tres retos analíticos:

«1) Las ciudades globales están incrustadas en la gobernanza global, por tanto, no pueden ser estudiadas como entidades separadas. 2) El surgimiento de las ciudades globales como actores diplomáticos en los asuntos internacionales no debe ocultar los procesos locales que se producen, pero tampoco mantener un significado puramente metafórico. 3) En sentido literal, los actores internacionales no son necesariamente "personas" ${ }^{117}$.

60. Para él, la importancia de incluir en el estudio de las RRII a las ciudades globales va más allá de una moda de insertar términos de la Sociología Urbana o el Urbanismo en la disciplina o de una nueva conciencia de lo urbano. En este sentido:

«Las ciudades globales desafían nuestros marcos de referencias dominantes y tradicionales de las RRII, trascendiendo la dimensión escalar (mundo, estado, región), así como las jerarquías políticas (supranacional, gubernamental, regional y local), alterando el sistema de soberanía westfaliano. Las actividades de estas ciudades nos recuerdan que la gobernabilidad del medio en donde están presentes las relaciones políticas de la humanidad son mucho más complejas, multi-escalares y variables, algo que la teoría de RRII no hace evidente» ${ }^{118}$.

61. En los últimos libros identificados, al menos para el estudio, es The Power of Cities in International Relations (2014) editado por Simon Curtis y Global Cities and Global Order (2017) escrito por el mismo autor, ambos tienen la intención de ilustrar si la relación entre la ciudad y el Estado-nación ha evolucionado de manera profunda, respondiendo al cuestionamiento: ¿Cómo las ciudades se han empoderado por los cambios estructurales en la política mundial? En donde el autor comenta que el resurgimiento de la ciudad a partir del Estado a finales del siglo xx fue facilitado por el propio Estado, a través del auge de las ciudades globales que son parte de un proceso más amplio de transformación del orden político internacional y del carácter de la sociedad internacional. En el primero, entre las contribuciones del texto se señala: 1) la naturaleza cambiante de las ciudades en el sistema internacional; 2) su creciente importancia en los resultados globales de gobernanza; 3) el poder financiero de las ciudades; 4) la acción de la ciudad en el ámbito de la seguridad; 5) la colaboración de las ciudades para hacer frente a los problemas ambientales; 6) las regiones urbanas transnacionales, y 7) los alcaldes como

117 Ibid., p. 58.

118 Acuto, M., "Global Cities: Gorillas in Our Midst», Alternatives, vol. 35, 2010, núm. 4, pp. 425448, esp. p. 429. 
actores internacionales ${ }^{119}$. En el segundo, este tipo de ciudades son las que catalizan las contradicciones dentro del sistema internacional contemporáneo, además de ser los sitios estratégicos para resolver dichas tensiones ${ }^{120}$.

\section{CRÍTICA A LOS ESTUDIOS DE LA CIUDAD GLOBAL Y LAS RRII}

62. La postura teórico-metodológica de la ciudad global y la formación de la red de ciudades mundiales ha recibido muchas críticas en su casi cuarenta años de existencia. La observación a las investigaciones centradas en las ciudades mundiales y globales del grupo GaWC, al igual que en las posturas de J. Friedmann, S. Sassen y M. Castells, es la del discurso preeminente en los estudios urbanos en la actualidad. G. del Cerro señala que «esta ha sido hasta ahora la posición hegemónica en las investigaciones sobre ciudades globales: la globalización se produce en unas pocas ciudades llamadas globales y el resto de lugares en el mundo reaccionan al proceso. Pero la respuesta local a las fuerzas globales no puede resumirse en una mera reacción pasiva; antes bien, se producen fenómenos de negociación, de resistencia, y finalmente de adaptación mediante transformación local» ${ }^{121}$.

63. Por su parte, Diane Davies identifica por qué en los últimos años en la Sociología Urbana estadounidense esta perspectiva se ha convertido en la hegemónica o mainstream y se ha popularizado en otros continentes y otras disciplinas:

«La fijación con ciudades de gran importancia económica (Tokio, Londres o Nueva York), y no meramente de un tamaño considerable (Ciudad de México, París, Los Ángeles). Esto implica que las ciudades identificadas como "globales" se distinguen porque su crecimiento económico no depende necesariamente de lo que se genera dentro de sus fronteras nacionales, sino de las redes más globales de producción y el consumo a las que pertenezcan. Esto también significa que estas ciudades son mucho menos propensas a ser vistas como grilletes para el desarrollo nacional de sus países de acogida.

Pareciera que se está produciendo un fenómeno relativamente nuevo con relación al enfoque geográfico, un cambio que a su vez pueden arrojar luz sobre las preguntas de investigación de los seguidores de esta perspectiva: ¿solo pueden existir en Estados desarrollados o pueden surgir en países en vías de desarrollo, emergentes o de ingresos medios? ¿Cuál es la función del Estado con relación a estas ciudades? ¿Cuál es la importancia o la función de las redes transnacionales, el territorio y la región donde se sitúan?»122.

64. La crítica principal se concentra sobre todo en el reduccionismo económico de los análisis, lo que provoca que el resultado sea relativamente el mismo, leído desde diversas perspectivas. Así, «el paradigma de la ciudad global avanza para conformar un objeto de estudio desde una perspectiva

119 CurTis, S. (ed.), The Power of Cities in International Relations, Londres, Routledge, 2014.

120 CuRTIS, S., Global Cities and Global Order, Oxford, Oxford University Press, 2017.

121 Del Cerro, G., op. cit., nota 73, p. 204.

122 Davis, D. E., op. cit., nota 1, pp. 99-100. 
casi eminentemente económica de la globalización» ${ }^{123}$. En opinión de Peter J. Taylor y Colin Flint, «el concepto de las ciudades mundiales es esencialmente un concepto de política económica, puesto que en su definición se entremezclan de forma indeleble la política y la economía» ${ }^{124}$. «Los detractores de la ciudad global aseguran que esta corriente solo observa y analiza ciertas características económicas puntuales y específicas y deja fuera todo un mosaico de variables que alteran y modifican, de manera drástica, el espacio urbano. Para ellos es necesario ampliar la visión y los estudios sobre la particularidad de la construcción de la urbe y observar un número mucho más amplio y diverso de ciudades» ${ }^{125}$, ya que no todas las ciudades del mundo entran en esta categoría.

65. Otro comentario es el relacionado a que «el análisis de la ciudad global es útil siempre y cuando se base en análisis detallados de ciudades particulares» ${ }^{126}$. Taylor y sus colaboradores, sin negar la importancia de cierto tipo de ciudades, señalan que «se sugiere que para la comprensión de la globalización a través de lentes urbanos se requiere el estudio de una gama más amplia de las ciudades. El futuro mundo urbano no constará de varios mini Nueva Yorks o mini Londres» ${ }^{127}$. «Las ciudades no crean per se las redes de ciudades. Son los gobiernos municipales los que pueden, construyen y/o apoyan la construcción de estas. Mediante el desarrollo de redes de infraestructura (aeropuertos, edificios inteligentes, etc.) las cuales no constituyen redes de ciudades. Son las personas, las mercancías y la información que fluyen a través de las infraestructuras las que definen las redes interurbanas» ${ }^{128}$.

«Suponiendo que los alcaldes de la ciudad optan por formar parte de la red, la cuestión radicaría en "cómo jugarían su mano". Por desgracia, uno de los efectos de la creación de las categorías "ciudad mundial" y "ciudad global" ha sido la creación de ejemplos de imitación de los modelos exitosos, es decir, se ha puesto en marcha un proceso de emulación. Esto ha tenido un impacto profundo a lo largo del orbe, ya que los gobiernos municipales han buscado y replicado un sinfín de políticas. Hay que hacer la aclaración, que la emulación podría resultar problemático» ${ }^{129}$.

66. Otra de sus críticas al paradigma de las ciudades globales, al menos en los trabajos más liberales, es que «el concepto de ciudad global no considera el largo periodo de formación, es decir, su carácter ahistórico» ${ }^{130}$. Pero esta omisión no necesariamente se refleja en los trabajos de Christopher Chase-Dunn ${ }^{131} \mathrm{o}$ en la perspectiva de Taylor sobre la formación de la red de

123 MéndeZ, A., op. cit., nota 3, p. 70.

124 TAYLOR, P. J. y Flint, C., op. cit., nota 38, p. 360.

125 Alfie, M., op. cit., nota 81, p. 185.

126 MÉndez, A., op. cit., nota 3, p. 70.

127 Taylor, P. J., Catalano, G. y Walker, D. R. F., op. cit., nota 60, p. 2375.

128 TAYLOR, P. J., op. cit., nota 62, p. 706.

129 TAYLOR, P. J. et al., op. cit., nota 13, p. 240.

130 KorfF, 1987: 486, citado por MÉnDEZ, A., op. cit., nota 3, p. 70.

131 Con planteamientos neomarxistas Chase Dunn ha acuñado el término de sistemas sociales de ciudades para definir a las redes de interacción humana y sus conexiones con los ambientes construi- 
ciudades. Tomando la perspectiva de la larga duración del sistema-mundo moderno, «las nuevas geografías políticas no son inusuales. [...] En otras palabras, la globalización anuncia una nueva espacialidad mundial para reemplazar el mosaico Westfaliano» ${ }^{132}$. Así, la conformación de la red de ciudades mundiales se considera que «es un proceso transhistórico presente desde que las ciudades han existido [...] el proceso de formación de la red se realiza a través de las actividades que los agentes económicos desempeñan al realizar sus prácticas comerciales habituales» ${ }^{133}$.

67. P. J. Taylor reconoce que la investigación de las ciudades mundiales «es fuerte en ideas, pero débil en evidencias» ${ }^{134}$, ya que presenta dos problemas: 1) De evidencia, debido a las deficiencias en la producción de datos que, por lo general, son generados por los Estados — «las estadísticas son la información recabada por los Estados, para propósitos del Estado»— ${ }^{135}$, además hay sesgos en los datos resultantes que suelen medir atributos en lugar de las relaciones. 2) De teoría, dentro de la investigación de las ciudades mundiales, la idea de una jerarquía y su conceptualización no se ha asumido a fondo, presumiblemente con el argumento de que las ciudades son inherentemente jerárquicas en sus relaciones ${ }^{136}$.

68. La gran crítica que se desprende a los textos de RRII que adaptan la perspectiva de la ciudad mundial y global, es que su objeto de estudio únicamente son las ciudades globales y sus redes transnacionales. Además queda claro que no todas las ciudades del mundo son globales y no todas pertenecen a este tipo de redes, por lo que dejan de lado iniciativas de inserción internacional más interesantes para ser investigadas y teorizadas. Asimismo centran toda su atención en su función e influencia en la gobernanza global, olvidándose de que también son actores importantes para la gobernanza multinivel, local y urbana, y que esa relevancia puede traducirse en la difusión de las buenas prácticas en políticas públicas desarrolladas en su territorio. Lo que es más, se olvidan por completo de la importancia de la imagen e identidad de estas ciudades para insertarse en el medio internacional.

69. Hay que recocer que existen ciudades con más recursos económicofinancieros, poder político y mayor población que otras. Estas han tenido la

\footnotetext{
dos y naturales. Para ellos, el sistema social es muy complejo, así el estudio de los sistemas de ciudad es una subcategoría de un asunto más general sobre los asentamientos. Véase CHASE-DunN, C. y ANDREW J., «Systems of cities», en McNicoll, G. y DEMENY, P. (eds.), Encyclopedia of Population, Nueva York, McMillan, 2003. ChaSE-Dunn, C., «The Changing Role of Cities in World-Systems», 1991/2004, http://www.irows.ucr.edu/cd/courses/10/reader/citrole/citrole.htm; CHASE-DUNN, C. y WILLARD, A., «Systems of Cities and World-Systems: Settlement Size Hierarchies and Cycles of Political Centralization, 2000BC-1988AD», Paper presented at the International Studies Association meeting, Acapulco, México, marzo de 1993.

132 TAYLOR, P. J., op. cit., nota 62, p. 704.

133 Ibid., nota 46, pp. 154-155.

134 Ibid., nota 83, p. 7.

135 Ibid., nota 46, p. 148.

136 Véase TAYLOR, P. J., op. cit., nota 43, p. 323.
} 
capacidad no solo de insertarse en la red global de ciudades mundiales, sino que tienen la capacidad de influir en las acciones de otras ciudades e intervenir en la gobernanza global así como en el Sistema Internacional. Desde el aspecto económico son los actores clave para el funcionamiento de la economía global, ya que es donde se producen y ofertan los servicios avanzados, y se sitúa el capital intelectual que los demanda.

70. Pero es importante destacar, y como se dijo en otro momento, «la actuación de las ciudades como fuerza política eficaz e influyente en la gobernanza global multinivel cobra cada vez más relevancia a partir del nuevo milenio. Una de las manifestaciones del potencial de la ciudad está, por ejemplo, en la provisión de soluciones a problemas locales que pueden ser escalables globalmente, y viceversa. De ahí el oportuno planteamiento de una agenda de investigación más allá de las establecidas por la paradiplomacia y la ciudad global que identifique categorías/variables clave que ayuden en la propuesta de trabajos de corte empírico, como puede ser la imagen, la agencia e identidad, tan necesarios para asentar y confirmar los presupuestos en torno a la ciudad en la gobernanza global multinivel» ${ }^{137}$.

\section{CONCLUSIONES}

71. Independientemente de sus detractores, y a manera de cierre, es gracias a las ciudades mundiales y globales, así como a sus redes formales e informales las que permitieron que la disciplina de RRII se comprometiera a realizar estudios más rigurosos de carácter cualitativo y cuantitativo. Lo que ha motivado a pensar en la generación de un posible espacio de articulación política del futuro más allá del Estado-nación, donde las ciudades tengan el peso que se merecen y que implica nuevos retos en el campo teóricoreflexivo y de la práctica política en la cuestión urbana, la geografía política y las RRII.

72. Hay que recordar que desde la década de los sesenta se ha escrito sobre las ciudades y su función dentro del Sistema Internacional, lo que ha permitido un aumento considerable de perspectivas teórico-metodológicas para entender la participación de aquellas en las RRII. En un primer lugar como un actor doméstico dentro de su Estado-nación, posteriormente como un actor internacional y en los últimos se está presentando como un agente en la gobernanza global. Cada perspectiva teórico-metodológica ha tenido su función principal para entender la importancia del estudio de la ciudad en el medio internacional.

73. Situar la problemática del estudio de la ciudad en el Sistema Internacional (Kenneth Boulding), identificar sus funciones y asumirla como actor internacional a través de sus relaciones transgubernamentales (Robert Keohane y Joseph Nye) como actor no estatal (Richard Mansbach, Yale Fer-

137 LARA, R. F. y Cerqueira, O., op. cit., nota 75, pp. 43-44. 
guson y Donald Lampert), y por ende, concebirlo como unidad de análisis a través de las relaciones mundiales de las ciudades (Chadwick F. Alger), reconociendo las partes que permiten su estudio como el gobierno local o no central (Panayotis Soldatos, Lee Radebaugh, Earl Fry, Karl Kresl) para realizar (para)diplomacia urbana (Miguel Martín, Nahuel Oddone, Parag Khanna, Rodrigo Tavares, André Aprigio, Pablo Sánchez Chillón), municipal (Vicenç Fisas,) o de ciudades (Rogier van der Pluijm, Jan Melissen, Fons van Overbeek, Arne Musch, Chris van der Valk, Alexandra Sizoo, Kian Tajbakhsh) o política exterior municipal y/o urbana (Heidi Hobbs, Andrew. Kirby, Sallie Marston, Kenneth Seasholes, Alexander Ugalde, Nico van der Heiden).

74. En el último lustro, ha ido en aumento su estudio con la intención de identificar su agencia en la actual gobernanza global de las ciudades (Vanessa Marx, Mark Amen, Patricia L. McCarney, Noah J. Toly, Klaus Segbers, Gerardo del Cerro, Tassilo Herrschel, Peter Newman, Ray Lara) a través de las ciudades globales (Simon Curtis, Taedong Lee, Kristin Ljungkvist) y sus redes (Sofie Bouteligier, Mónica Salomón, Corina McKendry) ya que actualmente son consideradas creadoras y catalizadoras de regímenes internacionales (Michele Acuto, Craig Johnson, Noah Toly, Heike Schroeder) gracias a su nuevo papel como actor político global (Benjamin Barber, Stijn Oosterlynck, Luce Beeckmans, David Bassens, Ben Derudder, Barbara Segaert, Luc Braeckmans) , además de su identidad e imagen, para poderla asumir como un sujeto de investigación (Simon Parker, Vicente Torrijos, Daniel Bell, Avner de-Shalit), y sujeto de derecho internacional con la intención de crear un derecho local internacional (Gerald Frug, David Barron, Yishai Blank, Janne Nijman, Susana Beltrán, Miguel Beltrán de Felipe, Helmut Philipp Aust, Anél du Plessis).

\section{RESUMEN}

\section{LAS CIUDADES MUNDIALES Y GLOBALES EN EL MEDIO INTERNACIONAL, UNA REVISIÓN TEÓRICO-METODOLÓGICA DESDE LAS RELACIONES INTERNACIONALES}

El presente estudio realiza un recuento del estado de la cuestión de los estudios de las Ciudades Mundiales y Globales desde las Relaciones Internacionales (RRII), que se han centrado en su influencia en la gobernanza global, su capacidad de creación de redes globales de interacción política y económica, y como actor dentro del Sistema Internacional. Como cualquier perspectiva teórico-metodológica ha recibido críticas que en su momento han tenido que resolver conforme se va consolidando una comunidad epistémica de la ciudad en la disciplina de las RRII. Este estudio tiene como premisa de trabajo que gracias al desarrollo durante la década de los ochenta a la actualidad de la escuela de la Ciudad Global desde la Geografía Política, la Economía y la Sociología Urbana ha permitido que dentro de las RRII en el último lustro sea la perspectiva mejor posicionada aunque no es la única.

Palabras clave: ciudad global, ciudad mundial, gobernanza global, teorías del ensamble, redes de ciudades, red de ciudades mundiales. 


\section{ABSTRACT \\ WORLD CITIES AND GLOBAL CITIES IN THE INTERNATIONAL MEDIUM, A THEORETICAL AND METHODOLOGICAL REVISION FROM INTERNATIONAL RELATIONS}

This paper summarizes the state of the art of the World and Global Cities studies which, adopting an International Relations point of view, have addressed the influence on global governance of World and Global Cities, together with their ability to create networks with political and economic interactions and their role as actors in the International System. Like all theoretical and methodological approaches, the one espoused by the above-mentioned studies has been subject to criticism, which has been tacked with in parallel to the consolidation of an epistemic community on the "city» in the discipline of International Relations. The author of this papers claims that thanks to the progress experienced since the eighties until today by the school of the Global City, its approach has become the best positioned perspective in the area of IR, although it is not the only one.

Keywords: global city, world city, global governance, ensemble theory, city networks, world city network. 